\title{
Die Wirkung von Insulin auf den Stoffwechsel der isolierten perfundierten Leber normaler und alloxandiabetischer Ratten
}

\author{
II. Stoffwechseländerungen unter dem Einfluß intraportaler Insulininfusionen*
}

\author{
H.D. Söling, P. Kneer, W. Drägert und W. Creutzfeldt
}

Aus der Medizinischen Universitätsklinik Göttingen (Direktor: Prof. Dr. W. CREutzFELDT) und der Medizinischen Universitätsklinik Freiburg i.Br. (Direktor: Prof. Dr. L. HEILMEYER)

Eingegangen am 25. November 1965

The effect of insulin on the metabolism of isolated perfused livers of normal and alloxan-diabetic rats. II. The changes in metabolism under the influence of intraportal insulin infusions.

Summary. Continuing previous experiments the influence of insulin on the metabolism of isolated perfused livers of normal and alloxan-diabetic rats was studied. In these experiments media with different concentrations of nonesterified fatty acids (NEFA) $(2.5-3.5 \mathrm{mEq} / \mathrm{l}$ and $0.30-0.65 \mathrm{mEq} / \mathrm{l}$ were used. In all experiments $0.9 \mathrm{U}$ of insulin/hr were infused intraportally throughout the experiment $(180 \mathrm{~min})$. The following results were obtained: 1. Insulin significantly increased the net glucose uptake of normal livers. The net glucose balance of livers from diabetic animals was not affected by insulin. Insulin diminished the increased glycogen synthesis of diabetic livers. 2. Insulin caused a significant decrease in the net amino acid production and a net uptake of $\alpha$-amino acids. The net production of urea by normal livers was not influenced by insulin, while the urea production of diabetic livers showed a slight but insignificant decrease. 3 . The delayed increase in the medium concentrations of lactate and pyruvate in experiments with diabetic livers, as opposed to normal livers, was distinctly, though not significantly accelerated by insulin. The lactate/pyruvate ratio $(\mathrm{L} / \mathrm{P} \cdot \mathrm{Q})$ of the medium, as well as the concentrations of potassium and inorganic phosphate ions in the medium were not significantly affected by insulin in experiments either with normal or with diabetic livers. The same was observed also in the magnitude of the liver blood flow. During insulin infusion the bile production by normal and diabetic livers rose slightly but not significantly. 4 . The experiments did not show the effect of insulin to be dependent on the NEFA-content of the medium. Our data demonstrate a direct and immediate effect of insulin on liver metabolism.

Effet de l'insuline sur le métabolisme des foies isolés et perfusés de rats normaux et alloxan-diabétiques. II. Modifications du métabolisme sous l'influence d'infusions intraportales d'insuline.

Résumé. Continuant les expériences précédentes, l'influence de l'insuline sur le métabolisme des foies isolés des rats normaux et alloxane-diabétiques a été étudiée. De milieux de concentrations différentes d'acides gras nonestérifiés (NEFA) $(2.5-3.5 \mathrm{mEq} / \mathrm{l}$ et $0.30-0.65 \mathrm{mEq} / \mathrm{l})$ ont été employés. Dans toutes ces expériences $0.9 \mathrm{U} / \mathrm{h}$ d'insuline ont été infusées dans la veine porte pendant la durée de l'expérience $(180 \mathrm{~min})$. Les résultats suivants ont été obtenus: 1. La captation nette de glucose par des foies normaux est augmentée par l' insuline de façon significative; le bilan net du glucose des foies diabétiques est

* Die Arbeit wurde mit Unterstützung durch die Deutsche Forschungsgemeinschaft, Bad Godesberg, durchgeführt. inchangé. Sous l'influence de l'insuline la synthèse de glycogène intensifiée diminue. 2. L'insuline provoque une diminution significative de la sécrétion d'acides $\alpha$-aminés et une captation nette d'acides $\alpha$-aminés. La production d'urée des foies normaux n'est pas influencée par l'insuline, tandis que celle des foies diabétiques diminue un peu, mais pas de façon significative. 3. L'accroissement retardé des concentrations de lactate et de pyruvate des foies diabétiques - comparé aux foies normaux - est un peu accéléré, mais pas de façon significative, par l'insuline. Le quotient lactate/pyruvate (L/P-Q) ainsi que les concentrations de potassium et de phosphate inorganique ne sont pas influencés par l'insuline, ni dans les foies normaux, ni dans les foies diabétiques. Il en est de même avec l'irrigation sanguine du foie. $L$ 'insuline provoque une augmentation non significative de la production de bile des foies normaux et diabétiques. 4. Les effets de l'insuline ne dépendent pas des concentrations de NEFA du milieu. Ces résultats démontrent un effet immédiat et direct de l'insuline sur le métabolisme du foie.

Zusammenfassung. In Fortsetzung vorausgegangener Experimente [23] wurde der Einfluß von Insulin auf den Stoffwechsel isolierter Lebern von normalen und alloxandiabetischen Ratten untersucht. - Dabei wurden Medien unterschiedlicher Konzentration an unveresterten Fettsäuren (NEFA) $(2.5-3.5 \mathrm{mval} / \mathrm{l}$ und $0.30-0.65 \mathrm{mval} / \mathrm{l})$ verwendet. In allen Versuchen wurden vom Versuchsbeginn an über die ganze Versuchsdauer von $180 \mathrm{~min}$ hinweg $0.9 \mathrm{E}$ Insulin/h intraportal infundiert. Dabei wurden fol. gende Befunde erhoben: 1. Die Nettoglucosebilanz normaler Lebern wurde durch Insulin im Sinne einer signifikanten Steigerung der Glucoseaufnahme beeinflußt, während die Nettoglucosebilanz der Leber von diabetischen Tieren unbeeinflußt blieb. Die verstärlzte Glykogensynthese diabetischer Lebern wurde durch Insulin vermindert. 2 . Insulin führte zu einer signifikanten Verminderung der Nettoaminosäureabgabe bzw. zu einer Nettoaufnahme von $\alpha$ Aminosäuren. Die Harnstoffbildung normaler Lebern wurde durch Insulin nicht beeinflußt, diejenige der diabetischen Lebern etwas, aber nicht signifikant gesenkt. 3. Der in Experimenten mit diabetischen Lebern im Vergleich zu normalen Lebern verzögert erfolgende Anstieg der Mediumkonzentrationen von Lactat und Pyruvat wurde durch Insulin etwas, aber noch nicht signifikant gesteigert. Das Verhalten des Lactat/Pyruvat-Quotienten (L/P-Q) im Medium sowie der Konzentrationen von Kalium und anorganischem Phosphat ließ weder in Experimenten mit normalen noch in solchen mit diabetischen Lebern eine signifikanto Beeinflussung durch Insulin erkennen. Das gleiche gilt für die Größe der Leberdurchblutung. Die Galleproduktion normaler und diabetischer Lebern war unter Insulin etwas, aber noch nicht signifikant erhöht. 4. Die Untersuchungen ergaben keine $A b$ hängigkeit der Insulinwirkung vom NEFA-Gehalt des Mediums. Die mitgeteilten Befunde sprechen für einen direkten Soforteffekt von Insulin auf den Leberstoffwechsel. 
In einer vorausgehenden Mitteilung [23] wurde über Untersuchungen an isolierten Lebern normaler und alloxandiabetischer Ratten unter verschiedenen experimentellen Bedingungen berichtet. In Fortführung dieser Experimente prüften wir die Wirkung intraportaler Insulininfusionen auf den Stoffwechsel der isolierten perfundierten Leber von normalen und alloxandiabetischen Ratten.

\section{Methodik}

Die Untersuchungen wurden wiederum an männlichen Sprague-Dawley-Ratten des Inzuchtstammes der ,Gesellschaft für Versuchstierzucht, Hannover" durchgeführt. Gewicht, Vorbereitung der Tiere, Ernährung wie früher angegeben [23]. Auch die Erzeugung des Alloxandiabetes erfolgte in der bereits beschriebenen Weise [23, 19]. Die Untersuchungen zur Insulinwirkung auf die Bilanzen von Harnstoff, Kalium und anorganischem Phosphat mußten an einem anderen Sprague-Dawley-Stamm durchgeführt werden, nachdem die Zucht der oben genannten Tiere eingestellt worden war. Aus diesem Grunde wurden hierfür auch Kontrollversuche ohne Insulin mit Lebern des neuen Sprague-Dawley-Stammes durchgeführt.
Die Zusammensetzung des Perfusionsmediums entsprach gleichfalls den früheren Angaben. Alle Versuche wurden mit einer Glucosekonzentration von 11.1 $\mathrm{mMol} / 1$ durchgeführt. Sofern nicht anders angegeben, lag die Ausgangskonzentration der unveresterten Fettsäuren zwischen 2.5 und $3.5 \mathrm{mval} / \mathrm{l}$. Es wurden aber außerdem Untersuchungen mit einem NEFA-armen Medium durchgeführt, bei dem die NEFA-Ausgangskonzentration nur $0.30-0.65 \mathrm{mval} / \mathrm{l}$ betrug. Dies wurde durch Verwendung eines anderen Rinderalbuminpräparates möglich (Einzelheiten s. [23 u. 19]). Die Versuche mit NEFA-armem Medium wurden direkt nach dem Einhängen der Leber in die Perfusionsapparatur begonnen, die Versuche mit NEFA-reichem Medium dagegen erst 20 Minuten später. Perfusionsapparatur, Operationstechnik und chemische Bestimmungsmethoden entsprachen den früheren Angaben [23]. In allen Experimenten wurden von Versuchsbeginn an $0.9 \mathrm{E}$ eines 10 fach umkristallierten Rinderinsulins der Firma NOVO ${ }^{1}$ pro Stunde über die ganze Versuchsdauer in den zur Pfortader führenden Schlauch infundiert (Infusionsvolumen $1.2 \mathrm{ml} / \mathrm{h}$ ).

1 Wir danken der Firma NOVO Industrie G.m.b.H., Mainz für die freundliche Ửberlassung dieses Insulins.

Tabelle 1. Änderungen der Glucosekonzentration in $m$ Mol/l im Medium bei Perfusion isolierter Lebern von normalen und diabetischen Ratten unter dem Einfluß einer dreistündigen intraportalen Dauerinfusion von 0.9 E Insulin/h. (Die Anderungen sind bezogen auf die Ausgangskonzentrationen bei $t=0$ und auf $10 \mathrm{~g}$ Leber)

\begin{tabular}{|c|c|c|c|c|c|c|c|c|}
\hline \multirow{2}{*}{ Lactat } & \multicolumn{8}{|c|}{ Zeit in Minuten } \\
\hline & 0 & 30 & 60 & 90 & 120 & 150 & 180 & n \\
\hline $\begin{array}{l}\text { Normal } \\
\text { ohne Insulin }\end{array}$ & 0 & $\begin{array}{l}+0.07 \\
\pm 0.56\end{array}$ & $\begin{array}{l}+0.28 \\
\pm 1.40\end{array}$ & $\begin{array}{l}+0.31 \\
\pm 1.51\end{array}$ & $\begin{array}{r}+0.44 \\
\pm 1.39\end{array}$ & $\begin{array}{l}+0.32 \\
\pm 1.51\end{array}$ & $\begin{array}{l}+0.10 \\
\pm 1.26\end{array}$ & 8 \\
\hline $\begin{array}{l}\text { Normal } \\
\text { mit Insulin }\end{array}$ & 0 & $\begin{array}{l}-0.20 \\
\pm 0.27\end{array}$ & $\begin{array}{l}-0.30 \\
\pm 0.40\end{array}$ & $\begin{array}{l}-0.40 \\
\pm 0.84\end{array}$ & $\begin{array}{l}-0.90 \\
\pm 0.91\end{array}$ & $\begin{array}{l}-1.40 \\
\pm 0.97\end{array}$ & $\begin{array}{l}-1.90 \\
\pm 1.32\end{array}$ & 5 \\
\hline$p-W e r t$ & & & & & & $<0.05$ & $<0.025$ & \\
\hline $\begin{array}{l}\text { Diabetisch } \\
\text { ohne Insulin }\end{array}$ & 0 & $\begin{array}{l}+0.27 \\
\pm 0.69\end{array}$ & $\begin{array}{l}+0.46 \\
\pm 0.81\end{array}$ & $\begin{array}{l}+0.74 \\
\pm 1.64\end{array}$ & $\begin{array}{l}+0.63 \\
\pm 1.64\end{array}$ & $\begin{array}{l}+1.15 \\
\pm 2.39\end{array}$ & $\begin{array}{l}+1.10 \\
\pm 3.60\end{array}$ & 5 \\
\hline $\begin{array}{l}\text { Diabetisch } \\
\text { mit Insulin }\end{array}$ & 0 & $\begin{array}{l}+0.87 \\
\pm 0.80\end{array}$ & $\begin{array}{l}+0.93 \\
\pm 1.58\end{array}$ & $\begin{array}{l}+0.54 \\
\pm 1.83\end{array}$ & $\begin{array}{l}+0.62 \\
\pm 2.70\end{array}$ & $\begin{array}{l}+0.64 \\
\pm 3.08\end{array}$ & $\begin{array}{l}+0.35 \\
\pm 2.93\end{array}$ & 5 \\
\hline$p-W e r t$ & & & & & & $>0.10$ & $>0.10$ & \\
\hline
\end{tabular}

Tabelle 2. Änderungen des Leberglykogengehaltes in g/100 g Feuchtleber bei Perfusion isolierter Lebern von normalen und diabetischen Ratten unter dem Einfluß einer dreistïndigen Dauerinfusion von $0.9 \mathrm{E} I \mathrm{Insulin} / \mathrm{h}$

\begin{tabular}{|c|c|c|c|c|c|c|c|c|}
\hline \multirow{2}{*}{ GIykogen } & \multicolumn{8}{|c|}{ Zeit in Minuten } \\
\hline & 0 & 30 & 60 & 90 & 120 & 150 & 180 & $\mathrm{n}$ \\
\hline $\begin{array}{l}\text { Normal } \\
\text { ohne Insulin }\end{array}$ & $\begin{array}{r}0.066 \\
\pm 0.039\end{array}$ & - & - & - & $\begin{array}{r}0.208 \\
+0.127\end{array}$ & - & $\begin{array}{r}0.239 \\
\pm 0.170\end{array}$ & 8 \\
\hline $\begin{array}{l}\text { Normal } \\
\text { mit Insulin }\end{array}$ & $\begin{array}{r}0.098 \\
\pm 0.081\end{array}$ & - & - & - & $\begin{array}{r}0.543 \\
\pm 0.530\end{array}$ & - & $\begin{array}{r}0.322 \\
+0.280\end{array}$ & 3 \\
\hline$p-W e r t$ & & & & & $>0.10$ & & $>0.25$ & \\
\hline $\begin{array}{l}\text { Diabetisch } \\
\text { ohne Insulin }\end{array}$ & $\begin{array}{c}0.399 \\
\pm 0.40\end{array}$ & - & - & - & $\begin{array}{r}0.707 \\
\pm 0.562\end{array}$ & - & $\begin{array}{r}0.690 \\
\pm 0.603\end{array}$ & 5 \\
\hline $\begin{array}{l}\text { Diabetisch } \\
\text { mit Insulin }\end{array}$ & $\begin{array}{r}1.280 \\
\pm 0.471\end{array}$ & & & & $\begin{array}{r}2.420 \\
\pm 1.800\end{array}$ & & $\begin{array}{r}0.700 \\
\pm 0.803\end{array}$ & 5 \\
\hline p-Wert & $<0.01$ & & & & $<0.05$ & & $>0.25$ & \\
\hline
\end{tabular}


In den Tabellen bedeutet + , daß die angegebene Konzentration höher, - , daß sie niedriger als die zugehörige Ausgangskonzentration liegt.

\section{Ergebnisse}

I. Die Wirkung einer intraportalen Insulininfusion auf den Stoffwechsel der normalen isolierten perfundierten Leber (NEFA-reiches Medium): Unter der Insulininfusion nimmt die Glucoseaufnahme im Mittel trotz der Streuung der Einzelversuche signifikant zu (s. Abb. 1 and Tab. 1). Der Leberglykogengehalt steigt während der Perfusion unter Insulin nicht signifikant stärker an (s. Tab. 2). Die nach 180 Minuten erreichten Konzentrationen von Lactat und Pyruvat im Medium liegen unter Insulin im Mittel höher. Der Unterschied ist jedoch noch nicht signifikant $(0.05>p<0.10)$ (s. Tab. $3 \mathrm{u} .4$ ). Die Lactatkonzentrationen haben ihren tiefsten Wert nach 90 Minuten, die Pyruvatkonzentrationen nach 60 Minuten erreicht. Bezieht man den Anstieg der Konzentrationen von Lactat und Pyruvat auf diese Zeitpunkte, so ist der Anstieg beider Metabolite bis zur 180. Minute unter Insulin um ca. 50\% stärker.

Das Verhalten des Lactat/Pyruvat-Quotienten $(L / P$ $Q)$ wird durch die Insulininfusion nicht wesentlich be- einflußt. Mit und ohne Insulin sinkt der L/P-Q kontinuierlich bis zur Versuchsmitte ab, um dann bis zum Versuchsende im Mittel wieder etwas anzusteigen (s. Abb. 2). Die Kinetik der NEFA-Aufnahme wird gleichfalls durch die Insulininfusion nicht signifikant beeinflußt (s. Tab. 6 und Abb. 3). Das gleiche gilt für die Änderungen der Gesamtketonkörperkonzentration (s. Abb. 2 und Tab. 7). Mit und ohne Insulin steigt die Ketonkörperkonzentration während der ersten Versuchshälfte um etwa den gleichen Betrag an und fällt in der zweiten Versuchshälfte wieder langsam ab. Demgegenüber wird die Aminosäurebilanz durch die Insulininfusion deutlich beeinflußt: Ohne Insulin steigt die $\alpha$-Amino-N-Konzentration während des ganzen Versuches kontinuierlich an. Unter Insulin fehlt dieser Anstieg (s. Abb. 4 u. Tab. 8). U̇ber einige Zeit hin läßt sich sogar eine deutliche Nettoaufnahme von $\alpha$-Aminosäuren nachweisen (s. Abb. 4).

Die Insulinwirkung auf die Konzentrationsänderungen von Harnstoff, Kalium und anorganischem Phosphat in Versuchen mit normalen Rattenlebern wurden in gesonderten Experimenten (ohne und mit Insulin) mit einem anderen Sprague-Dawley-Stamm durchgeführt (s. Methodik). Die Ergebnisse sind Tab. 9 zu entnehmen. Das Verhalten der Konzentrations-

Tabelle 3. Anderungen der Lactatkonzentration in mMolll im Medium bei Perfusion isolierter Lebern von normalen und diabetischen Ratten unter dem Einfluß einer dreistündigen intraportalen Dauerinfusion von $0,9 \mathrm{E}$ Insulin/h

\begin{tabular}{|c|c|c|c|c|c|c|c|c|}
\hline \multirow{2}{*}{ Lactat } & \multicolumn{8}{|c|}{ Zeit in Minuten } \\
\hline & 0 & 30 & 60 & 90 & 120 & 150 & 180 & $\mathrm{n}$ \\
\hline $\begin{array}{l}\text { Normal } \\
\text { ohne Insulin }\end{array}$ & $\begin{array}{r}0.730 \\
\pm 0.224\end{array}$ & $\begin{array}{r}0.565 \\
+0.123\end{array}$ & $\begin{array}{r}0.406 \\
\pm 0.185\end{array}$ & $\begin{array}{r}0.366 \\
\pm 0.162\end{array}$ & $\begin{array}{r}0.441 \\
+0.232\end{array}$ & $\begin{array}{r}0.648 \\
+0.331\end{array}$ & $\begin{array}{r}0.932 \\
+0.407\end{array}$ & $\begin{array}{l}8 \\
8\end{array}$ \\
\hline $\begin{array}{l}\text { Normal } \\
\text { mit Insulin }\end{array}$ & $\begin{array}{r}0.513 \\
+0.139\end{array}$ & $\begin{array}{r}0.451 \\
\pm 0.185\end{array}$ & $\begin{array}{r}0.410 \\
\pm 0.170\end{array}$ & $\begin{array}{r}0.263 \\
\pm 0.295\end{array}$ & $\begin{array}{r}0.409 \\
\pm 0.450\end{array}$ & $\begin{array}{r}0.738 \\
+0.660\end{array}$ & $\begin{array}{r}1.258 \\
\pm 0.710\end{array}$ & 3 \\
\hline $\mathrm{p}$-Wert & & & & & & & $>0.05$ & \\
\hline $\begin{array}{l}\text { Diabetisch } \\
\text { ohne Insulin }\end{array}$ & $\begin{array}{r}1.330 \\
\pm 0.690\end{array}$ & $\begin{array}{r}0.950 \\
\pm 0.450\end{array}$ & $\begin{array}{r}0.650 \\
+0.185\end{array}$ & $\begin{array}{r}0.330 \\
\pm \quad 0.082\end{array}$ & $\begin{array}{r}0.260 \\
\pm 0.118\end{array}$ & $\begin{array}{r}0.270 \\
\pm 0.114\end{array}$ & $\begin{array}{r}0.430 \\
\pm 0.186\end{array}$ & 5 \\
\hline $\begin{array}{l}\text { Diabetisch } \\
\text { mit Insulin }\end{array}$ & $\begin{array}{r}1.010 \\
+0.597\end{array}$ & $\begin{array}{r}0.870 \\
\pm 0.267\end{array}$ & $\begin{array}{r}0.590 \\
+0.220\end{array}$ & $\begin{array}{r}0.460 \\
\pm 0.220\end{array}$ & $\begin{array}{r}0.410 \\
\pm 0.361\end{array}$ & $\begin{array}{r}0.470 \\
\pm 0.331\end{array}$ & $\begin{array}{r}0.690 \\
\pm 0.400\end{array}$ & 5 \\
\hline $\mathrm{p}$-Wert & & & & & & $>0.05$ & $>0.05$ & \\
\hline
\end{tabular}

Tabelle 4. Anderungen der Pyruvatkonzentration in $m M o l / l$ im Medium bei Perfusion isolierter Lebern von normalen und diabetischen Ratten unter dem Einfluß einer dreistündigen intraportalen Dauerinfusion von $0,9 \mathrm{E}$ Insulin/h

\begin{tabular}{|c|c|c|c|c|c|c|c|c|}
\hline \multirow{2}{*}{ Pyruvat } & \multicolumn{8}{|c|}{ Zeit in Minuten } \\
\hline & 0 & 30 & 60 & 90 & 120 & 150 & 180 & $\mathrm{n}$ \\
\hline $\begin{array}{l}\text { Normal } \\
\text { ohne Insulin }\end{array}$ & $\begin{array}{r}0.065 \\
+0.022\end{array}$ & $\begin{array}{r}0.045 \\
\pm 0.009\end{array}$ & $\begin{array}{r}0.042 \\
\pm 0.006\end{array}$ & $\begin{array}{r}0.053 \\
+0.017\end{array}$ & $\begin{array}{r}0.086 \\
\pm 0.034\end{array}$ & $\begin{array}{r}0.117 \\
+0.085\end{array}$ & $\begin{array}{r}0.146 \\
\pm 0.058\end{array}$ & 8 \\
\hline $\begin{array}{l}\text { Normal } \\
\text { mit Insulin }\end{array}$ & $\begin{array}{r}0.043 \\
+0.018\end{array}$ & $\begin{array}{r}0.035 \\
+0.013\end{array}$ & $\begin{array}{r}0.034 \\
+0.014\end{array}$ & $\begin{array}{r}0.062 \\
+0.039\end{array}$ & $\begin{array}{r}0.082 \\
\pm 0.042\end{array}$ & $\begin{array}{r}0.111 \\
\pm 0.021\end{array}$ & $\begin{array}{r}0.180 \\
\pm 0.071\end{array}$ & 3 \\
\hline p-Wert & & & & & & & $>0.05$ & \\
\hline $\begin{array}{l}\text { Diabetisch } \\
\text { ohne Insulin }\end{array}$ & $\begin{array}{r}0.047 \\
\pm 0.011\end{array}$ & $\begin{array}{r}0.036 \\
\pm 0.006\end{array}$ & $\begin{array}{r}0.040 \\
\pm 0.015\end{array}$ & $\begin{array}{r}0.029 \\
+0.011\end{array}$ & $\begin{array}{r}0.029 \\
+0.012\end{array}$ & $\begin{array}{r}0.049 \\
\pm 0.017\end{array}$ & $\begin{array}{r}0.077 \\
\pm 0.042\end{array}$ & 5 \\
\hline $\begin{array}{l}\text { Diabetisch } \\
\text { mit Insulin }\end{array}$ & $\begin{array}{r}0.051 \\
+0.009\end{array}$ & $\begin{array}{r}0.033 \\
\pm 0.006\end{array}$ & $\begin{array}{r}0.033 \\
+0.001\end{array}$ & $\begin{array}{r}0.054 \\
+0.055\end{array}$ & $\begin{array}{r}0.062 \\
+0.071\end{array}$ & $\begin{array}{r}0.087 \\
+0.067\end{array}$ & $\begin{array}{r}0.117 \\
\pm 0.066\end{array}$ & 5 \\
\hline $\mathrm{p}$-Wert & & & & & & & $>0.05$ & \\
\hline
\end{tabular}


Tabelle 5. Änderungen des Lactat/Pyruvat-Quotienten (L/P-Q) im Medium bei Perfusion isolierter Lebern von normalen und diabetischen Ratten unter dem Einfuß einer dreistïndigen intraportalen Dauerinfusion von $0.9 \mathrm{E}$ Insulin/h

\begin{tabular}{|c|c|c|c|c|c|c|c|c|}
\hline \multirow{2}{*}{$\mathrm{L} / \mathrm{P}-\mathrm{Q}$} & \multicolumn{8}{|c|}{ Zeit in Minuten } \\
\hline & 0 & 30 & 60 & 90 & 120 & 150 & 180 & $\mathrm{n}$ \\
\hline $\begin{array}{l}\text { Normal } \\
\text { ohne Insulin }\end{array}$ & $\begin{array}{r}11.1 \\
\pm 4.0\end{array}$ & $\begin{array}{r}12.5 \\
\pm 4.0\end{array}$ & $\begin{array}{r}9.7 \\
\pm 3.5\end{array}$ & $\begin{array}{r}6.9 \\
\pm 6.1\end{array}$ & $\begin{array}{r}5.1 \\
\pm 1.7\end{array}$ & $\begin{array}{r}5.5 \\
\pm 1.1\end{array}$ & $\begin{array}{r}6.4 \\
\pm 1.6\end{array}$ & 8 \\
\hline $\begin{array}{l}\text { Normal } \\
\text { mit Insulin }\end{array}$ & $\begin{array}{r}11.9 \\
\pm 2.7\end{array}$ & $\begin{array}{r}12.9 \\
\pm 1.2\end{array}$ & $\begin{array}{r}12.0 \\
\pm 1.8\end{array}$ & $\begin{array}{r}4.3 \\
\pm 1.8\end{array}$ & $\begin{array}{r}5.0 \\
\pm 3.2\end{array}$ & $\begin{array}{r}6.6 \\
\pm 4.8\end{array}$ & $\begin{array}{r}7.0 \\
\pm 1.3\end{array}$ & 3 \\
\hline p-Wert & $>0.25$ & & & & & & $>0.25$ & \\
\hline $\begin{array}{l}\text { Diabetisch } \\
\text { ohne Insulin }\end{array}$ & $\begin{array}{r}28.2 \\
\pm 11.6\end{array}$ & $\begin{array}{r}26.4 \\
\pm 13.5\end{array}$ & $\begin{array}{r}16.3 \\
\pm 7.6\end{array}$ & $\begin{array}{r}11.4 \\
\pm 3.4\end{array}$ & $\begin{array}{r}9.0 \\
\pm 4.4\end{array}$ & $\begin{array}{r}5.5 \\
\pm 2.8\end{array}$ & $\begin{array}{r}5.6 \\
\pm 1.7\end{array}$ & 5 \\
\hline $\begin{array}{l}\text { Diabetisch } \\
\text { mit Insulin }\end{array}$ & $\begin{array}{r}19.6 \\
\pm 4.0\end{array}$ & $\begin{array}{r}26.2 \\
\pm 6.7\end{array}$ & $\begin{array}{r}17.9 \\
\pm 6.7\end{array}$ & $\begin{array}{r}8.5 \\
\pm 6.8\end{array}$ & $\begin{array}{r}6.6 \\
\pm 2.8\end{array}$ & $\begin{array}{r}5.4 \\
\pm 1.4\end{array}$ & $\begin{array}{r}5.9 \\
\pm 1.7\end{array}$ & 5 \\
\hline p-Wert & $>0.10$ & $>0.25$ & & & & & $>0.25$ & \\
\hline
\end{tabular}

Tabelle 6. Änderungen der Konzentration der unveresterten Fettsäuren (NEFA) in mval/l im Medium bei Perfusion isolierter Lebern von normaten und diabetischen Ratten unter dem Einfluß einer dreistündigen intraportalen Dauerinfusion von $0.9 \mathrm{E}$ Insulin/h. (Die Änderungen sind bezogen auf die Ausgangskonzentrationen bei $t=0$ und auf $10 \mathrm{~g}$ Leber)

\begin{tabular}{|c|c|c|c|c|c|c|c|c|}
\hline \multirow{2}{*}{ NEFA } & \multicolumn{8}{|c|}{ Zeit in Minuten } \\
\hline & 0 & 30 & 60 & 90 & 120 & 150 & 180 & $\mathrm{n}$ \\
\hline $\begin{array}{l}\text { Normal } \\
\text { ohne Insulin }\end{array}$ & 0 & $\begin{array}{l}-1.36 \\
\pm 0.65\end{array}$ & $\begin{array}{l}-2.25 \\
\pm 0.80\end{array}$ & $\begin{array}{l}-2.39 \\
\pm 0.86\end{array}$ & $\begin{array}{r}-2.54 \\
\pm 1.06\end{array}$ & $\begin{array}{l}-2.58 \\
\pm 1.01\end{array}$ & $\begin{array}{l}-2.61 \\
\pm 1.06\end{array}$ & 8 \\
\hline $\begin{array}{l}\text { Normal } \\
\text { mit Insulin }\end{array}$ & 0 & $\begin{array}{l}-1.26 \\
\pm 0.38\end{array}$ & $\begin{array}{l}-2.23 \\
\pm 0.14\end{array}$ & $\begin{array}{l}-2.58 \\
\pm 0.35\end{array}$ & $\begin{array}{l}-2.70 \\
\pm 0.44\end{array}$ & $\begin{array}{l}-2.78 \\
\pm 0.38\end{array}$ & $\begin{array}{l}-2.83 \\
\pm 0.48\end{array}$ & 6 \\
\hline p-Wert & & & & & & & $>0.25$ & \\
\hline $\begin{array}{l}\text { Diabetisch } \\
\text { ohne Insulin }\end{array}$ & 0 & $\begin{array}{l}-1.71 \\
\pm 0.30\end{array}$ & $\begin{array}{l}-2.71 \\
\pm 0.45\end{array}$ & $\begin{array}{l}-3.00 \\
\pm 0.56\end{array}$ & $\begin{array}{l}-3.25 \\
\pm 0.56\end{array}$ & $\begin{array}{l}-3.21 \\
\pm 0.59\end{array}$ & $\begin{array}{l}-3.27 \\
\pm 0.57\end{array}$ & 5 \\
\hline $\begin{array}{l}\text { Diabetisch } \\
\text { mit Insulin }\end{array}$ & 0 & $\begin{array}{l}-1.69 \\
\pm 0.35\end{array}$ & $\begin{array}{l}-2.54 \\
\pm 0.31\end{array}$ & $\begin{array}{l}-2.90 \\
\pm 0.28\end{array}$ & $\begin{array}{l}-2.98 \\
\pm 0.30\end{array}$ & $\begin{array}{l}-3.08 \\
\pm 0.33\end{array}$ & $\begin{array}{l}-3.12 \\
\pm 0.26\end{array}$ & 6 \\
\hline$p-W e r t$ & & & & & & & $>0.25$ & \\
\hline
\end{tabular}

Tabelle 7. Änderungen der Konzentration der Gesamtketonkörper in mMol/l im Medium bei Perfusion isolierter Lebern von normalen und diabetischen Ratten unter dem Einfuß einer dreistündigen intraportalen Infusion von $0,9 \mathrm{E}$ Insulin/h. (Die Änderungen sind bezogen auf die Ausgangskonzentrationen bei $t=0$ und auf $10 \mathrm{~g}$ Leber)

\begin{tabular}{|c|c|c|c|c|c|c|c|c|}
\hline \multirow{2}{*}{ Gesamt-Ketonkörper } & \multicolumn{8}{|c|}{ Zeit in Minuten } \\
\hline & 0 & 30 & 60 & 90 & 120 & 150 & 180 & $\mathrm{n}$ \\
\hline $\begin{array}{l}\text { Normal } \\
\text { ohne Insulin }\end{array}$ & 0 & $\begin{array}{l}+2.90 \\
\pm 0.57\end{array}$ & $\begin{array}{l}+4.65 \\
\pm 0.91\end{array}$ & $\begin{array}{l}+4.75 \\
\pm 0.48\end{array}$ & $\begin{array}{l}+4.16 \\
\pm 0.87\end{array}$ & $\begin{array}{l}+3.65 \\
\pm 0.90\end{array}$ & $\begin{array}{l}+3.25 \\
\pm 0.82\end{array}$ & 8 \\
\hline $\begin{array}{l}\text { Normal } \\
\text { mit Insulin }\end{array}$ & 0 & $\begin{array}{l}+2.45 \\
\pm 0.22\end{array}$ & $\begin{array}{l}+4.30 \\
\pm 0.57\end{array}$ & $\begin{array}{l}+4.35 \\
\pm 0.48\end{array}$ & $\begin{array}{l}+3.55 \\
\pm 0.15\end{array}$ & $\begin{array}{l}+3.48 \\
\pm 0.67\end{array}$ & $\begin{array}{l}+3.00 \\
\pm 1.08\end{array}$ & 4 \\
\hline $\mathrm{p}$-Wert & & & & $>0.25$ & & & $>0.25$ & \\
\hline $\begin{array}{l}\text { Diabetisch } \\
\text { ohne Insulin }\end{array}$ & 0 & $\begin{array}{l}+3.63 \\
\pm 1.05\end{array}$ & $\begin{array}{l}+5.06 \\
\pm 1.17\end{array}$ & $\begin{array}{l}+5.45 \\
\pm 0.98\end{array}$ & $\begin{array}{l}+5.61 \\
\pm 1.31\end{array}$ & $\begin{array}{l}+5.01 \\
\pm 1.29\end{array}$ & $\begin{array}{l}+4.55 \\
\pm 1.38\end{array}$ & 5 \\
\hline $\begin{array}{l}\text { Diabetisch } \\
\text { mit Insulin }\end{array}$ & 0 & $\begin{array}{l}+2.40 \\
\pm 1.44\end{array}$ & $\begin{array}{l}+4.15 \\
\pm 1.31\end{array}$ & $\begin{array}{r}+4.40 \\
+1.20\end{array}$ & $\begin{array}{l}+4.66 \\
\pm 1.29\end{array}$ & $\begin{array}{l}+3.35 \\
\pm 1.20\end{array}$ & $\begin{array}{l}+1.92 \\
\pm 1.18\end{array}$ & 5 \\
\hline$p$-Wert & & & & $>0.05$ & $>0.05$ & $<0.05$ & $>0.05$ & \\
\hline
\end{tabular}

änderungen dieser drei Parameter wird durch Insulin nicht signifikant beeinflußt.

Der Leberblutfluß liegt unter Insulin im ganzen etwas höher, die Unterschiede sind aber nur teilweise signifikant (s. Tab. 10). Die Galleproduktion ist unter Insulin etwas, aber nicht signifikant erhöht (s. Tab. 11).
II. Die Wirkung einer intraportalen Insulininfusion auf den Stoffwechsel der normalen isolierten perfundierten Rattenleber bei Verwendung eines NEFAarmen Mediums: Auch in diesen Versuchen wird die Glucosebilanz durch Insulin in Richtung einer stärkeren Nettoaufnahme verschoben. Die Unterschiede sind aber noch nicht signifikant (s. Tab. 


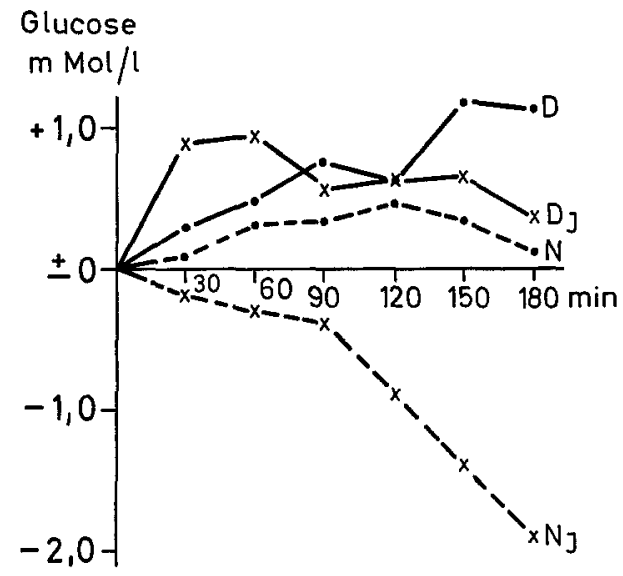

Abb. 1. Ānderungen der Glucosekonzentration im Medium während der Perfusion isolierter Leber von normalen (N) und diabetischen (D) Ratten ohne und mit ( $\mathrm{N}_{\text {I }}$ bzw. DI) intraportaler Infusion von $0.9 \mathrm{E}$ Insulin/h. Die Änderungen sind auf $10 \mathrm{~g}$ Leber sowie die $=0$ gesetzten Ausgangskonzentrationen bezogen
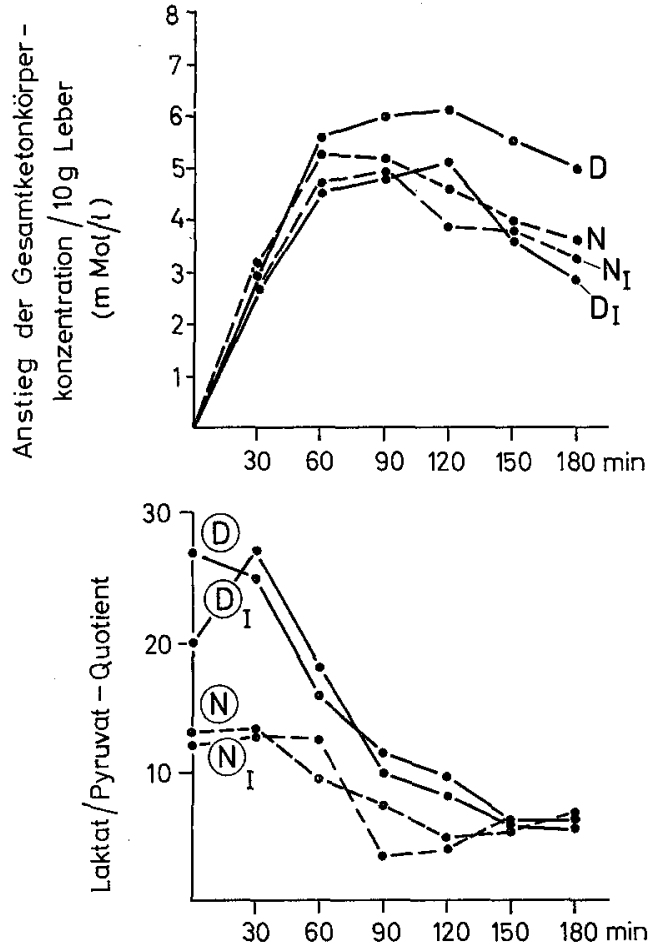

Abb. 2. Änderungen der Gesamtketonkörperkonzentration (ob. Kurve) und des Lactat/Pyruvat-Quotienten im Medium (unt. Kurve) während der Perfusion isolierter Lebern von normalen (N) und diabetischen (D) Ratten ohne und mit ( $\mathrm{N}_{\mathrm{I}}$ bzw. $\mathrm{D}_{\mathrm{I}}$ ) intraportaler Infusion von $0.9 \mathrm{E}$ Insulin $/ \mathrm{h}$. Die Änderungen der Gesamtketonkörperkonzentration sind auf $10 \mathrm{~g}$ Leber sowie die $=0$ ge setzten Ausgangskonzentrationen bezogen

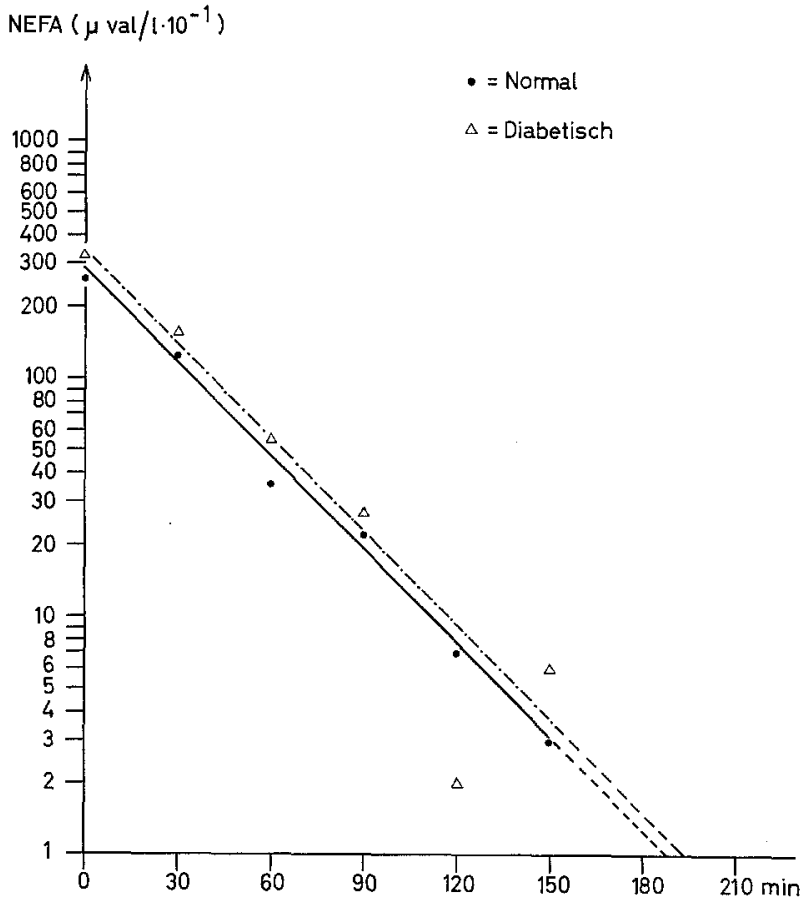

Abb. 3. Änderungen der Konzentration der unveresterten Fettsäuren (NEFA) im Medium bei Perfusion isolierter Lebern von normalen Ratten ohne und mit intraportaler Infusion von $0.9 \mathrm{E}$ Insulin/h. Die Änderungen sind auf $10 \mathrm{~g}$ Leber bezogen. Jeder Punkt entspricht dem Mittelwert aus 6-8 Einzelversuchen

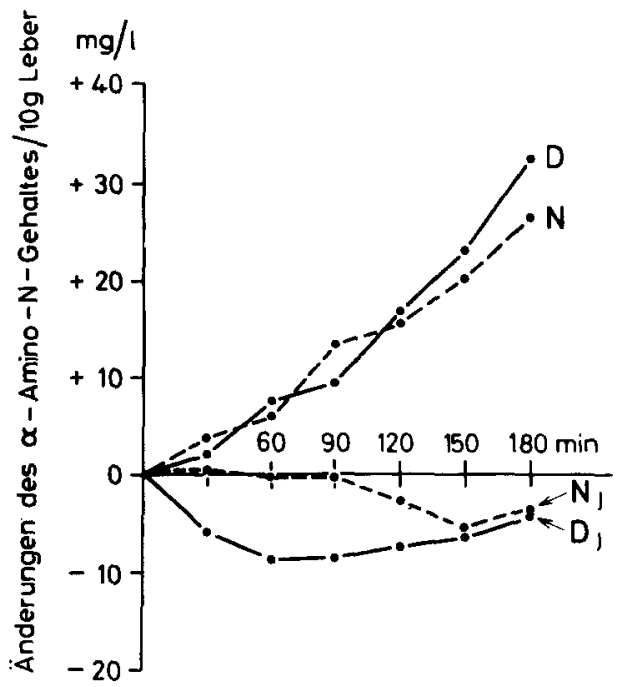

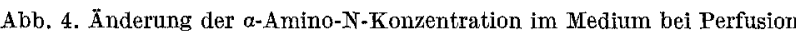
isolierter Lebern von normalen $(\mathrm{N})$ und diabetischen $(\mathrm{D})$ Ratten ohne und mit ( $\mathrm{N}_{\mathrm{I}}$ bzW. $\mathrm{D}_{\mathrm{I}}$ ) intraportaler Infusion von $0.9 \mathrm{E}$ Insulin/h. Die Änderungen sind auf $10 \mathrm{~g}$ Leber sowie die $=0$ gesetzten Ausgangskonzentrationen bezogen 
12). Der Zuwachs an Leberglykogen ist im Mittel unter Insulin erhöht. Der Unterschied ist aber nicht signifikant (s. Tab. 13). Ebenso ist der Anstieg der Konzentrationen von Lactat und Pyruvat bezogen auf die niedrigste im Verlaufe des Versuches erreichte Konzentration um ca. 50\% höher, wenn Insulin infundiert wurde (s. Tab. 14 u. 15). Auch das Verhalten des $L / P-Q$ entspricht den mit NEFA-reichem $\mathrm{Me}-$ dium erzielten Ergebnissen (s. Tab. 16). Der Galle$f l u \beta$ ist unter Insulin im Mittel deutlich erhöht. Der Unterschied ist aber noch nicht signifikant $(0.05>$ $0<0.10$ ) (s. Tab. 17). In 2 Versuchen wurde die Insulinwirkung auf das Verhalten der $\alpha$-Amino-N-Konzentration untersucht. In beiden Experimenten war unter Insulin eine deutliche Nettoaufnahme von $\alpha$ Aminosäuren nachweisbar, während die $\alpha$-Amino-NKonzentration ohne Insulin auch bei Verwendung eines NEFA-armen Mediums einen kontinuierlichen Anstieg zeigte.

III. Die Wirkung einer intraportalen Insulininfusion auf den Stoffwechsel der diabetischen isolierten perfundierten Rattenleber (NEFA-reiches Medium): Die im Mittel verstärkte Nettoglucoseabgabe durch diabetische Lebern ist unter Insulin etwas, aber nicht signifikant vermindert (s. Abb. 1 u. Tab. 1). Obwohl der Leberglykogengehalt in dieser Versuchsgruppe zu Versuchsbeginn deutlich höher lag als in den Versuchen mit diabetischen Lebern ohne Insulininfusion, kommt es nur im ersten Versuchsabschnitt zu einem Anstieg der Glykogenkonzentration. Im letzten Versuchsdrittel fällt der Leberglykogengehalt unter den Ausgangswert (s. Tab. 2). Dieses Verhalten des Glykogengehaltes war in 4 von 5 Versuchen nachweisbar. Der bei Perfusion diabetischer Lebern zu beobachtende verzögerte Anstieg der Konzentrationen von Lactat und Pyruvat wird durch Insulin nur insignifikant gesteigert und erreicht nicht die Höhe der NormalLeberversuche ohne Insulin (Tab. 3 und 4). Das Verhalten des $L / P-Q$ wird gleichfalls durch Insulin nicht signifikant beeinflußt (s. Abb. 2 und Tab. 5).

Die Kinetik der NEFA-Aufnahme durch diabetische Lebern wird durch Insulin genau so wenig beeinflußt wie diejenige der normalen Lebern (s. Tab. 6 und $\mathrm{Abb}$. 5). Die Veränderungen der Ketonkörperkonzentration entsprechen in etwa denjenigen, die in den Versuchen mit normalen Lebern mit und ohne Insulininfusion zu beobachten waren (s. Tab. 7 bzw. $A b b .2)$. Im Vergleich zu den Experimenten mit diabetischen Lebern ohne intraportale Insulininfusion liegen die Werte im ganzen etwas tiefer. Ein signifikanter Unterschied ist jedoch nur nach 15 min nachweisbar (s. Abb. 2 u. Tab. 7).

Die Nettoharnstoffabgabe der diabetischen Leber ist unter Insulin im Mittel um ca. 20\% geringer. In Anbetracht der großen Streuungen der Einzelversuche ist der Unterschied jedoch nicht signifikant (s. Tab. 18).

Dagegen wird die Aminosäurebilanz der diabetischen Leber durch die intraportale Insulininfusion in gleicher Weise beeinflußt wie diejenige normaler Lebern: An-

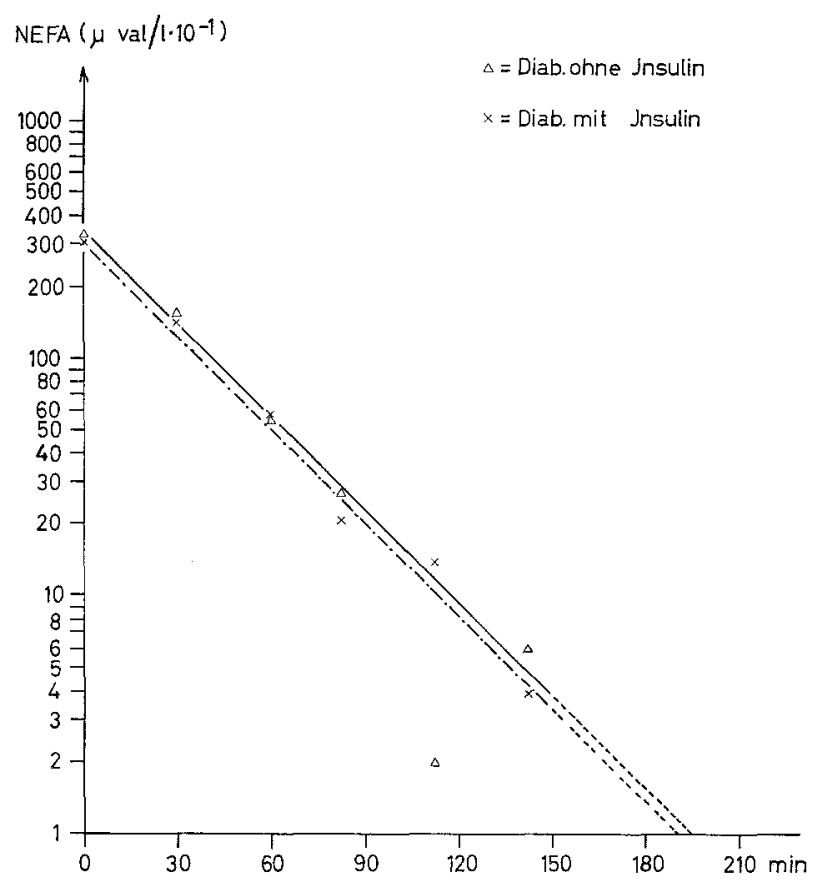

Abb. 5. Anderungen der Konzentration der unveresterten Fettsäuren (NEFA) im Medium während der Perfusion isolierter Lebern von diabetischen Ratten ohne und mit intraportaler Infusion von $0.9 \mathrm{E}$ Insulin/h. Die Ergebnisse sind auf $10 \mathrm{~g}$ Leber bezogen. Jeder Punkt entspricht dem Mittelwert aus 5 bzw. 6 Einzelversuchen.

stelle einer kontinuierlichen Netto-Abgabe von Aminosäuren in das Perfusionsmedium läßt sich innerhalb der ersten $60 \mathrm{~min}$ eine deutliche Nettoaufnahme nachweisen (s. Abb. 4 u. Tab. 8). Im Mittel hat die $\alpha$-AminoN-Konzentration auch nach 3 Stunden den Ausgangswert noch nicht erreicht (s. Abb. 4). Der Effekt von Insulin auf die Aminosäurebilanz der diabetischen Leber ist signifikant (s. Tab. 8).

Die Konzentrationsänderungen von anorganischem Phosphat und Kalium lassen demgegenüber keinen signifikanten Insulineffekt erkennen (s. Tab. 18). Das gleiche gilt für den Leberdurchfluß (s. Tab. 10). Die im Vergleich zu normalen Lebern etwas geringere Galleproduktion diabetischer Lebern ist unter Insulin etwas, aber insignifikant gesteigert (s. Tab. 11).

IV. Die Wirkung einer intraportalen Insulininfusion auf den Stoffwechsel diabetischer isolierter perfundierter Rattenlebern bei Verwendung eines NEFA-armen Perfusionsmediums: Der Anstieg der Glucosekonzentration wird durch Insulin nicht signifikant beeinflußt. Im Mittel steigt die Glucosekonzentration sogar in den Insulinversuchen stärker an (s. Tab. 12). Wie in den Versuchen mit NEFA-reichem Medium liegt auch in dieser Versuchsreihe die Glykogenkonzentration nach 3 Stunden tiefer als der Ausgangswert, während der Glykogengehalt ohne Insulininfusion deutlich angestiegen war (s. Tab. 13).

Die Einschränkung des Konzentrationsanstieges von Lactat und Pyruvat in Experimenten mit diabetischen Lebern wird durch die intraportale Insulin- 
Tabelle 8. Anderungen der Konzentration des $\alpha$-Amino-N in $m g / l$ im Medium bei Perfusion isolierter Lebern von normalen und diabetischen Ratten unter dem Einfluß einer dreistündigen intraportalen Dauerinfusion von $0.9 \mathrm{E}$ Insulin/h. (Die Änderungen sind bezogen auf die Ausgangskonzentration bei $t=0$ und auf $10 \mathrm{~g}$ Leber)

\begin{tabular}{|c|c|c|c|c|c|c|c|c|}
\hline \multirow{2}{*}{$\alpha$-Amino- $N$} & \multicolumn{8}{|c|}{ Zeit in Minuten } \\
\hline & 0 & 30 & 60 & 90 & 120 & 150 & 180 & $\mathbf{n}$ \\
\hline $\begin{array}{l}\text { Normal } \\
\text { ohne Insulin }\end{array}$ & 0 & $\begin{array}{l}+4.1 \\
\pm 2.7\end{array}$ & $\begin{array}{l}+6.8 \\
\pm 3.2\end{array}$ & $\begin{array}{r}+13.5 \\
\pm 3.4\end{array}$ & $\begin{array}{r}+15.7 \\
\pm 3.1\end{array}$ & $\begin{array}{r}+20.2 \\
\pm 6.0\end{array}$ & $\begin{array}{r}+26.3 \\
\pm 5.8\end{array}$ & 8 \\
\hline $\begin{array}{l}\text { Normal } \\
\text { mit Insulin }\end{array}$ & 0 & $\begin{array}{l}+0.4 \\
\pm 3.5\end{array}$ & $\begin{array}{l}-0.1 \\
\pm 3.9\end{array}$ & $\begin{array}{l}-0.2 \\
\pm 5.5\end{array}$ & $\begin{array}{l}-2.7 \\
\pm 3.1\end{array}$ & $\begin{array}{l}-5.2 \\
\pm 3.3\end{array}$ & $\begin{array}{l}-3.7 \\
\pm 5.4\end{array}$ & 5 \\
\hline p-Wert & & & & $<0.005$ & $<0.001$ & $<0.001$ & $<0.001$ & \\
\hline $\begin{array}{l}\text { Diabetisch } \\
\text { ohne Insulin }\end{array}$ & 0 & $\begin{array}{l}+2.2 \\
\pm 1.9\end{array}$ & $\begin{array}{l}+7.7 \\
\pm 2.9\end{array}$ & $\begin{array}{l}+9.6 \\
\pm 2.8\end{array}$ & $\begin{array}{r}+16.6 \\
\pm 5.0\end{array}$ & $\begin{array}{r}+23.6 \\
\pm 6.3\end{array}$ & $\begin{array}{r}+32.5 \\
\pm 4.8\end{array}$ & 5 \\
\hline $\begin{array}{l}\text { Diabetisch } \\
\text { mit Insulin }\end{array}$ & 0 & $\begin{array}{l}-6.0 \\
\pm 3.5\end{array}$ & $\begin{array}{l}-8.6 \\
\pm 5.8\end{array}$ & $\begin{array}{l}-8.4 \\
\pm 4.0\end{array}$ & $\begin{array}{l}-7.2 \\
\pm 3.1\end{array}$ & $\begin{array}{l}-6.2 \\
\pm 3.3\end{array}$ & $\begin{array}{l}-3.9 \\
\pm 5.4\end{array}$ & 10 \\
\hline p-Wert & & $<0.05$ & $<0.005$ & $<0.001$ & $<0.001$ & $<0.001$ & $<0.001$ & \\
\hline
\end{tabular}

Tabelle 9. Änderungen der Konzentration des Harnstoff- $N$, des anorganischen Phosphats ( $P_{i}$ ) und des Kaliums in $m M$ Mol bzw. mval/l im Medium bei Perfusion isolierter Lebern von normalen Ratten unter dem Einfluß einer dreistïndigen intraportalen Dauerinfusion von 0,9 E Insulin/h. (Die Anderungen sind bezogen auf die Ausgangskonzentrationen bei $t=0$ und auf $10 \mathrm{~g}$ Leber)

\begin{tabular}{|c|c|c|c|c|c|c|c|c|}
\hline \multirow{2}{*}{ Harnstoff-N } & \multicolumn{8}{|c|}{ Zeit in Minuten } \\
\hline & 0 & 30 & 60 & 90 & 120 & 150 & 180 & $\mathrm{n}$ \\
\hline $\begin{array}{l}\text { Normal } \\
\text { ohne Insulin }\end{array}$ & 0 & $\begin{array}{l}+0.25 \\
\pm 0.08\end{array}$ & $\begin{array}{r}+0.43 \\
\pm 0.15\end{array}$ & $\begin{array}{l}+0.54 \\
\pm 0.16\end{array}$ & $\begin{array}{l}+0.76 \\
\pm 0.30\end{array}$ & $\begin{array}{l}+0.82 \\
\pm 0.46\end{array}$ & $\begin{array}{l}+1.09 \\
\pm 0.50\end{array}$ & 6 \\
\hline $\begin{array}{l}\text { Normal } \\
\text { mit Insulin }\end{array}$ & 0 & $\begin{array}{l}+0.28 \\
\pm 0.14\end{array}$ & $\begin{array}{l}+0.35 \\
\pm 0.14\end{array}$ & $\begin{array}{l}+0.51 \\
\pm 0.20\end{array}$ & $\begin{array}{l}+0.68 \\
\pm 0.25\end{array}$ & $\begin{array}{l}+0.89 \\
\pm 0.31\end{array}$ & $\begin{array}{l}+1.18 \\
\pm 0.37\end{array}$ & 6 \\
\hline $\mathrm{p}$-Wert & & & & & & & $>0.30$ & \\
\hline$\underline{\mathrm{Pi}}$ & 0 & 30 & 60 & 90 & 120 & 150 & 180 & $\mathbf{n}$ \\
\hline $\begin{array}{l}\text { Normal } \\
\text { ohne Insulin }\end{array}$ & 0 & $\begin{array}{l}+0.07 \\
\pm 0.10\end{array}$ & $\begin{array}{l}+0.16 \\
\pm 0.12\end{array}$ & - & $\begin{array}{l}+0.28 \\
\pm 0.14\end{array}$ & - & $\begin{array}{l}+0.48 \\
\pm 0.21\end{array}$ & 5 \\
\hline $\begin{array}{l}\text { Normal } \\
\text { mit Insulin }\end{array}$ & 0 & $\begin{array}{l}+0.05 \\
\pm 0.02\end{array}$ & $\begin{array}{l}+0.14 \\
\pm 0.04\end{array}$ & - & $\begin{array}{l} \pm 0.25 \\
\pm 0.06\end{array}$ & - & $\begin{array}{l} \pm 0.49 \\
\pm 0.06\end{array}$ & 5 \\
\hline p-Wert & & & & & & & $>0.10$ & \\
\hline Kalium & 0 & 30 & 60 & 90 & 120 & 150 & 180 & $\mathbf{n}$ \\
\hline $\begin{array}{l}\text { Normal } \\
\text { ohne Insulin }\end{array}$ & 0 & $\begin{array}{l}+0.05 \\
\pm 0.20\end{array}$ & $\begin{array}{l}+0.26 \\
\pm 0.10\end{array}$ & $\begin{array}{l}+0.75 \\
\pm 0.29\end{array}$ & $\begin{array}{l}+0.84 \\
\pm 0.35\end{array}$ & $\begin{array}{l}+0.97 \\
\pm 0.40\end{array}$ & $\begin{array}{l}+1.22 \\
\pm 1.66\end{array}$ & 5 \\
\hline $\begin{array}{l}\text { Normal } \\
\text { mit Insulin }\end{array}$ & 0 & $\begin{array}{l}+0.07 \\
\pm 0.02\end{array}$ & $\begin{array}{l}+0.27 \\
\pm 0.11\end{array}$ & $\begin{array}{l} \pm 0.62 \\
\pm 0.08\end{array}$ & $\begin{array}{l}+0.93 \\
\pm 0.18\end{array}$ & $\begin{array}{l}+1.20 \\
\pm 0.45\end{array}$ & $\begin{array}{l}+1.72 \\
\pm 0.97\end{array}$ & 6 \\
\hline$p-W e r t$ & & & & & & & $>0.30$ & \\
\hline
\end{tabular}

Tabelle 10. Anderungen des Leberdurchflusses in ml/10 g Leber/min bei Perfusion isolierter Lebern von normalen und diabetischen Ratten unter dem Einfluß einer dreistündigen Dauerinfusion von $0.9 \mathrm{E}$ Insulin/h

\begin{tabular}{|c|c|c|c|c|c|c|c|c|}
\hline \multirow{2}{*}{ LeberdurchfluB } & \multicolumn{8}{|c|}{ Zeit in Minuten } \\
\hline & 0 & 30 & 60 & 90 & 120 & 150 & 180 & $\mathrm{n}$ \\
\hline $\begin{array}{l}\text { Normal } \\
\text { ohne Insulin }\end{array}$ & $\begin{array}{r}21.0 \\
\pm 3.3\end{array}$ & $\begin{array}{r}24.6 \\
\pm 6.4\end{array}$ & $\begin{array}{r}27.6 \\
\pm 6.9\end{array}$ & $\begin{array}{r}28.1 \\
\pm 7.0\end{array}$ & $\begin{array}{r}27.5 \\
\pm 7.7\end{array}$ & $\begin{array}{r}24.1 \\
\pm 4.8\end{array}$ & $\begin{array}{r}23.6 \\
\pm 3.5\end{array}$ & 8 \\
\hline $\begin{array}{l}\text { Normal } \\
\text { mit Insulin }\end{array}$ & $\begin{array}{r}27.0 \\
\pm 5.0\end{array}$ & $\begin{array}{r}31.1 \\
\pm 4.1\end{array}$ & $\begin{array}{r}30.2 \\
\pm 6.2\end{array}$ & $\begin{array}{r}30.9 \\
\pm 6.1\end{array}$ & $\begin{array}{r}27.0 \\
\pm 3.2\end{array}$ & $\begin{array}{r}33.2 \\
\pm 4.5\end{array}$ & $\begin{array}{r}30.8 \\
\pm 6.8\end{array}$ & 5 \\
\hline $\mathrm{p}-$ Wert & $<0.05$ & & & $>0.25$ & & & $<0.05$ & \\
\hline $\begin{array}{l}\text { Diabetisch } \\
\text { ohne Insulin }\end{array}$ & $\begin{array}{r}23.0 \\
\pm 7.0\end{array}$ & $\begin{array}{r}28.1 \\
+11.0\end{array}$ & $\begin{array}{r}30.2 \\
\pm 10.0\end{array}$ & $\begin{array}{r}31.0 \\
\pm 9.1\end{array}$ & $\begin{array}{r}30.9 \\
\pm 9.2\end{array}$ & $\begin{array}{r}31.0 \\
\pm 9.0\end{array}$ & $\begin{array}{r}29.1 \\
\pm 11.2\end{array}$ & 5 \\
\hline $\begin{array}{l}\text { Diabetisch } \\
\text { mit Insulin }\end{array}$ & $\begin{array}{r}23.1 \\
\pm 4.2\end{array}$ & $\begin{array}{r}29.0 \\
\pm 3.9\end{array}$ & $\begin{array}{r}30.0 \\
\pm 5.1\end{array}$ & $\begin{array}{r}30.1 \\
\pm 4.0\end{array}$ & $\begin{array}{r}29.0 \\
\pm 5.1\end{array}$ & $\begin{array}{r}27.9 \\
\pm 6.0\end{array}$ & $\begin{array}{r}30.1 \\
\pm 4.9\end{array}$ & 6 \\
\hline p-Wert & $>0.25$ & & & $>0.25$ & & & $>0.25$ & \\
\hline
\end{tabular}


Tabelle 11. Verhalten des Galleflusses in ml/10 g Leber bei Perfusion isolierter Lebern von normalen und diabetischen Ralten unter dem Einfluß einer dreistündigen intraportalen Dauerinfusion von $0.9 \mathrm{E}$ Insulin/h

\begin{tabular}{|c|c|c|c|c|c|c|c|c|}
\hline \multirow{2}{*}{ Gallefluß } & \multicolumn{8}{|c|}{ Zeit in Minuten } \\
\hline & 0 & 30 & 60 & 90 & 120 & 150 & 180 & $\mathrm{n}$ \\
\hline $\begin{array}{l}\text { Normal } \\
\text { ohne Insulin }\end{array}$ & & & $\begin{array}{r}0.77 \\
\pm 0.31\end{array}$ & & $\begin{array}{r}1.22 \\
\pm 0.50\end{array}$ & & $\begin{array}{r}1.60 \\
\pm 0.73\end{array}$ & 8 \\
\hline $\begin{array}{l}\text { Normal } \\
\text { mit Insulin }\end{array}$ & & & $\begin{array}{r}0.80 \\
\pm 0.25\end{array}$ & & $\begin{array}{r}1.40 \\
\pm 0.41\end{array}$ & & $\begin{array}{r}1.90 \\
\pm 0.66\end{array}$ & 4 \\
\hline$p-$ Wert & & & $>0.25$ & & $>0.10$ & & $>0.10$ & \\
\hline $\begin{array}{l}\text { Diabetisch } \\
\text { ohne Insulin }\end{array}$ & & & $\begin{array}{r}0.50 \\
\pm 0.01\end{array}$ & & $\begin{array}{r}0.90 \\
\pm 0.10\end{array}$ & & $\begin{array}{r}1.20 \\
\pm 0.30\end{array}$ & 5 \\
\hline $\begin{array}{l}\text { Diabetisch } \\
\text { mit Insulin }\end{array}$ & & & $\begin{array}{r}0.60 \\
\pm 0.20\end{array}$ & & $\begin{array}{r}1.10 \\
\pm 0.70\end{array}$ & & $\begin{array}{r}1.40 \\
\pm 0.30\end{array}$ & 5 \\
\hline$p$-Wert & & & $>0.05$ & & $>0.05$ & & $>0.05$ & \\
\hline
\end{tabular}

Tabelle 12. Änderungen der Glucosekonzentration in mMol/l im Medium bei Perfusion isolierter Lebern von normalen und diabetischen Ratten unter dem Einfluß einer Dauerinfusion von $0.9 \mathrm{E}$ Insulin/h (NEF A-armes Medium!). (Die Anderungen sind bezogen auf die Ausgangskonzentrationen bei $t=0$ und auf $10 \mathrm{~g}$ Leber)

\begin{tabular}{|c|c|c|c|c|c|c|c|}
\hline \multirow{2}{*}{ Glucose } & \multicolumn{7}{|c|}{ Zeit in Minuten } \\
\hline & 0 & 30 & 60 & 100 & 140 & 180 & $\mathbf{n}$ \\
\hline $\begin{array}{l}\text { Normal } \\
\text { ohne Insulin }\end{array}$ & 0 & $\begin{array}{l}+0.88 \\
\pm 0.91\end{array}$ & $\begin{array}{l}+0.47 \\
\pm 1.05\end{array}$ & $\begin{array}{l}-0.04 \\
\pm 1.11\end{array}$ & $\begin{array}{l}-0.78 \\
\pm 1.66\end{array}$ & $\begin{array}{l}-0.79 \\
\pm 1.53\end{array}$ & 8 \\
\hline $\begin{array}{l}\text { Normal } \\
\text { mit Insulin }\end{array}$ & 0 & $\begin{array}{l}+0.86 \\
\pm 0.67\end{array}$ & $\begin{array}{l}-0.06 \\
\pm 1.41\end{array}$ & $\begin{array}{l}-0.66 \\
\pm 1.33\end{array}$ & $\begin{array}{l}-1.39 \\
\pm 1.76\end{array}$ & $\begin{array}{l}-2.07 \\
\pm 1.76\end{array}$ & 6 \\
\hline $\mathrm{p}$-Wert & & & & & & $>0.05$ & \\
\hline $\begin{array}{l}\text { Diabetiseh } \\
\text { ohne Insulin }\end{array}$ & 0 & $\begin{array}{l}+0.71 \\
\pm 0.72\end{array}$ & $\begin{array}{l}+0.69 \\
\pm 0.85\end{array}$ & $\begin{array}{l}+0.67 \\
\pm 1.32\end{array}$ & $\begin{array}{l}+0.12 \\
\pm 1.92\end{array}$ & $\begin{array}{l}+0.18 \\
\pm 1.61\end{array}$ & 10 \\
\hline $\begin{array}{l}\text { Diabetisch } \\
\text { mit Insulin }\end{array}$ & 0 & $\begin{array}{l}+1.88 \\
+1.51\end{array}$ & $\begin{array}{l}+2.45 \\
\pm 1.86\end{array}$ & $\begin{array}{l}+2.43 \\
\pm 1.45\end{array}$ & $\begin{array}{l}+2.51 \\
\pm 1.77\end{array}$ & $\begin{array}{l}+2.28 \\
\pm 2.00\end{array}$ & 5 \\
\hline $\mathrm{p}-$ Wert & & & & & & $<0.05$ & \\
\hline
\end{tabular}

Tabelle 13. Änderungen des Glykogengehaltes in g/100 g Feuchtleber bei Perfusion isolierter Lebern von normalen und diabetischen Ratten unter dem Einfuß einer dreistündigen intraportalen Dauerinfusion von 0.9. E Insulin/h (NEF A-armes Medium!)

\begin{tabular}{|c|c|c|c|c|c|c|c|}
\hline \multirow{2}{*}{ Glykogengehalt } & \multicolumn{7}{|c|}{ Zeit in Minuten } \\
\hline & 0 & 30 & 60 & 100 & 140 & 180 & n \\
\hline $\begin{array}{l}\text { Normal } \\
\text { ohne Insulin }\end{array}$ & $\begin{array}{r}0.071 \\
\pm 0.051\end{array}$ & & & & & $\begin{array}{r}0.178 \\
\pm 0.106\end{array}$ & 5 \\
\hline $\begin{array}{l}\text { Normal } \\
\text { mit Insulin }\end{array}$ & $\begin{array}{r}0.067 \\
\pm 0.034\end{array}$ & & & & & $\begin{array}{r}0.350 \\
\pm 0.340\end{array}$ & 5 \\
\hline p-Wert & $>0.20$ & & & & & $>0.10$ & \\
\hline $\begin{array}{l}\text { Diabetisch } \\
\text { ohne Insulin }\end{array}$ & $\begin{array}{r}0.434 \\
\pm 0.417\end{array}$ & & & & & $\begin{array}{r}1.004 \\
\pm 0.577\end{array}$ & 8 \\
\hline $\begin{array}{l}\text { Diabetisch } \\
\text { mit Insulin }\end{array}$ & $\begin{array}{r}0.385 \\
\pm 0.589\end{array}$ & & & & & $\begin{array}{r}0.248 \\
\pm 0.127\end{array}$ & 5 \\
\hline $\mathrm{p} \cdot$ Wert & $>0.20$ & & & & & $<0.001$ & \\
\hline
\end{tabular}


Tabelle 14. Änderungen der Konzentration von Lactat in mMol/l im Medium bei Perfusion isolierter Lebern von normalen und diabetischen Ratten unier dem Einfluß einer dreistündigen Dauerinfusion von $0.9 E$ Insulin/h

(NEF A-armes Medium!)

\begin{tabular}{|c|c|c|c|c|c|c|c|}
\hline \multirow{2}{*}{ Lactat } & \multicolumn{7}{|c|}{ Zeit in Minuten } \\
\hline & 0 & 30 & 60 & 100 & 140 & 180 & $\mathbf{n}$ \\
\hline $\begin{array}{l}\text { Normal } \\
\text { ohne Insulin }\end{array}$ & $\begin{array}{r}0.686 \\
\pm 0.214\end{array}$ & $\begin{array}{r}0.493 \\
\pm 0.256\end{array}$ & $\begin{array}{r}0.503 \\
\pm 0.304\end{array}$ & $\begin{array}{r}0.782 \\
\pm 0.281\end{array}$ & $\begin{array}{r}0.984 \\
\pm 0.504\end{array}$ & $\begin{array}{r}1.027 \\
\pm 0.593\end{array}$ & 6 \\
\hline $\begin{array}{l}\text { Normal } \\
\text { mit Insulin }\end{array}$ & $\begin{array}{r}0.483 \\
\pm 0.112\end{array}$ & $\begin{array}{r}0.359 \\
\pm 0.189\end{array}$ & $\begin{array}{r}0.401 \\
\pm 0.116\end{array}$ & $\begin{array}{r}0.431 \\
\pm 0.337\end{array}$ & $\begin{array}{r}0.848 \\
\pm 0.519\end{array}$ & $\begin{array}{r}1.272 \\
\pm 0.551\end{array}$ & 6 \\
\hline p-Wert & & & & & & $>0.10$ & \\
\hline $\begin{array}{l}\text { Diabetisch } \\
\text { ohne Insulin }\end{array}$ & $\begin{array}{r}0.990 \\
\pm 0.599\end{array}$ & $\begin{array}{r}0.597 \\
\pm 0.375\end{array}$ & $\begin{array}{r}0.501 \\
\pm 0.228\end{array}$ & $\begin{array}{r}0.420 \\
\pm 0.245\end{array}$ & $\begin{array}{r}0.513 \\
\pm 0.225\end{array}$ & $\begin{array}{r}0.624 \\
+0.174\end{array}$ & 10 \\
\hline $\begin{array}{l}\text { Diabetisch } \\
\text { mit Insulin }\end{array}$ & $\begin{array}{r}0.898 \\
+0.231\end{array}$ & $\begin{array}{r}0.599 \\
\pm 0.276\end{array}$ & $\begin{array}{r}0.308 \\
\pm 0.235\end{array}$ & $\begin{array}{r}0.339 \\
+0.209\end{array}$ & $\begin{array}{r}0.395 \\
\pm 0.190\end{array}$ & $\begin{array}{r}0.509 \\
+0.167\end{array}$ & 5 \\
\hline p-Wert & & & & & & $>0.05$ & \\
\hline
\end{tabular}

Tabelle 15. Anderungen der Konzentration von Pyruvat in mMolll im Medium bei Perfusion isolierter Lebern von normalen und diabetischen Ratten unter dern Einfluß einer dreistündigen intraportalen Dauerinfusion von $0.9 \mathrm{E}$ Insulin/h (NEF A-armes Medium!)

\begin{tabular}{|c|c|c|c|c|c|c|c|}
\hline \multirow{2}{*}{ Pyruvat } & \multicolumn{7}{|c|}{ Zeit in Minuten } \\
\hline & 0 & 30 & 60 & 100 & 140 & 180 & $\mathrm{n}$ \\
\hline $\begin{array}{l}\text { Normal } \\
\text { ohne Insulin }\end{array}$ & $\begin{array}{r}0.052 \\
\pm 0.025\end{array}$ & $\begin{array}{r}0.042 \\
\pm 0.016\end{array}$ & $\begin{array}{r}0.078 \\
\pm 0.040\end{array}$ & $\begin{array}{r}0.099 \\
\pm 0.048\end{array}$ & $\begin{array}{r}0.129 \\
\pm 0.041\end{array}$ & $\begin{array}{r}0.155 \\
+0.049\end{array}$ & 6 \\
\hline $\begin{array}{l}\text { Normal } \\
\text { mit Insulin }\end{array}$ & $\begin{array}{r}0.042 \\
\pm 0.015\end{array}$ & $\begin{array}{r}0.034 \\
+0.011\end{array}$ & $\begin{array}{r}0.044 \\
\pm 0.025\end{array}$ & $\begin{array}{r}0.094 \\
+0.072\end{array}$ & $\begin{array}{r}0.149 \\
+0.079\end{array}$ & $\begin{array}{r}0.189 \\
\pm 0.064\end{array}$ & 6 \\
\hline$p$-Wert & & & & & & $>0.05$ & \\
\hline $\begin{array}{l}\text { Diabetisch } \\
\text { ohne Insulin }\end{array}$ & $\begin{array}{r}0.043 \\
\pm 0.013\end{array}$ & $\begin{array}{r}0.033 \\
\pm 0.017\end{array}$ & $\begin{array}{r}0.042 \\
\pm 0.099\end{array}$ & $\begin{array}{r}0.060 \\
+0.055\end{array}$ & $\begin{array}{r}0.068 \\
\pm 0.029\end{array}$ & $\begin{array}{r}0.093 \\
\pm 0.056\end{array}$ & 10 \\
\hline $\begin{array}{l}\text { Diabetiseh } \\
\text { mit Insulin }\end{array}$ & $\begin{array}{r}0.032 \\
\pm 0.009\end{array}$ & $\begin{array}{r}0.026 \\
\pm 0.010\end{array}$ & $\begin{array}{r}0.028 \\
\pm 0.012\end{array}$ & $\begin{array}{r}0.041 \\
\pm 0.018\end{array}$ & $\begin{array}{r}0.053 \\
\pm 0.018\end{array}$ & $\begin{array}{r}0.074 \\
\pm 0.046\end{array}$ & 5 \\
\hline $\mathrm{p}$-Wert & & & & & & $>0.10$ & \\
\hline
\end{tabular}

Tabelle 16. Änderungen des Lactat/Pyruvat-Quotienten (L/P-Q) im Medium bei Perfusion isolierter Lebern von normalen und diabetischen Ratten unter dem Einfluß einer dreistündigen Dauerinfusion von 0.9 E Insulin/h (NEF $A$-armes $M$ edium!)

\begin{tabular}{|c|c|c|c|c|c|c|c|}
\hline \multirow{2}{*}{$\mathrm{L} / \mathrm{P}-\mathrm{Q}$} & \multicolumn{7}{|c|}{ Zeit in Minuten } \\
\hline & 0 & 30 & 60 & 100 & 140 & 180 & $\mathrm{n}$ \\
\hline $\begin{array}{l}\text { Normal } \\
\text { ohne Insulin }\end{array}$ & $\begin{array}{r}13.2 \\
\pm 4.0\end{array}$ & $\begin{array}{r}11.7 \\
\pm 9.5\end{array}$ & $\begin{array}{r}6.5 \\
+2.9\end{array}$ & $\begin{array}{r}7.9 \\
+2.6\end{array}$ & $\begin{array}{r}7.6 \\
\pm 4.6\end{array}$ & $\begin{array}{r}6.6 \\
\pm 3.0\end{array}$ & 6 \\
\hline $\begin{array}{l}\text { Normal } \\
\text { mit Insulin }\end{array}$ & $\begin{array}{r}11.5 \\
\pm 2.2\end{array}$ & $\begin{array}{r}10.5 \\
\pm 4.3\end{array}$ & $\begin{array}{r}9.1 \\
\pm 3.5\end{array}$ & $\begin{array}{r}4.6 \\
\pm 1.9\end{array}$ & $\begin{array}{r}5.7 \\
\pm 4.2\end{array}$ & $\begin{array}{r}6.7 \\
\pm 0.9\end{array}$ & 6 \\
\hline$p$-Wert & & & & & & $>0.10$ & \\
\hline $\begin{array}{l}\text { Diabetisch } \\
\text { ohne Insulin }\end{array}$ & $\begin{array}{r}23.0 \\
\pm 10.2\end{array}$ & $\begin{array}{r}18.0 \\
\pm 15.3\end{array}$ & $\begin{array}{r}11.9 \\
+10.1\end{array}$ & $\begin{array}{r}7.0 \\
\pm \mathbf{5 . 3}\end{array}$ & $\begin{array}{r}7.5 \\
+9.3\end{array}$ & $\begin{array}{r}6.7 \\
\pm 11.0\end{array}$ & 10 \\
\hline $\begin{array}{l}\text { Diabetisch } \\
\text { mit Insulin }\end{array}$ & $\begin{array}{r}28.0 \\
\pm 10.4\end{array}$ & $\begin{array}{r}23.0 \\
\pm 9.1\end{array}$ & $\begin{array}{r}11.0 \\
\pm 5.4\end{array}$ & $\begin{array}{r}8.3 \\
\pm 6.5\end{array}$ & $\begin{array}{r}7.5 \\
\pm 2.3\end{array}$ & $\begin{array}{r}6.9 \\
\pm 13.5\end{array}$ & 5 \\
\hline $\mathrm{p}$-Wert & & & & & & $>0.25$ & \\
\hline
\end{tabular}

Tabelle 17. Verhalten des Galleflusses in ml/10 g Leber bei Perfusion isolierter Lebern von normalen und diabetischen Ratten unter dem Einfuß einer dreistündigen intraportalen Dauerinfusion von 0.9 Insulin/h (NEFA-armes Medium!)

\begin{tabular}{|c|c|c|c|c|}
\hline & $\begin{array}{l}\text { Normal } \\
\text { ohne Insulin }\end{array}$ & $\begin{array}{l}\text { Normal } \\
\text { mit Insulin }\end{array}$ & $\begin{array}{l}\text { Diabetisch } \\
\text { ohne Insulin }\end{array}$ & $\begin{array}{l}\text { Diabetisch } \\
\text { mit Insulin }\end{array}$ \\
\hline $\begin{array}{l}\text { Gallefluß } \\
\text { (ml/10 g Leber/3 Std.) } \\
\text { p-Wert }\end{array}$ & $\begin{array}{l}1.27 \pm 0.46 \\
(\mathrm{n}=6)\end{array}$ & $\begin{array}{l}1.97 \pm 0.92 \\
(\mathrm{n}=5)\end{array}$ & $\begin{array}{l}1.41 \div 0.47 \\
(\mathrm{n}=9)\end{array}$ & $\begin{array}{l}1.51+\frac{1}{ \pm} 0.43 \\
(\mathrm{n}=5)\end{array}$ \\
\hline
\end{tabular}


Tabelle 18. Anderungen der Konzentration des Harnstoff- $N$, des anorganischen Phosphats $\left(P_{i}\right)$ und des $K a$ liums in mMol bzw. mvall im Medium bei Perfusion isolierter Lebern von diabetischen Ratten unter dem Einfuß einer dreistündigen intraportalen Dauerinfusion von $0.9 \mathrm{E}$ Insulin/h. (Die Anderungen sind bezogen auf die Ausgangskonzentrationen bei $t=0$ und auf $10 \mathrm{~g}$ Leber)

\begin{tabular}{|c|c|c|c|c|c|c|c|c|}
\hline \multirow{2}{*}{ Harnstoff- $N$} & \multicolumn{8}{|c|}{ Zeit in Minuten } \\
\hline & $\overline{0}$ & 30 & 60 & 90 & 120 & 150 & 180 & $\mathrm{n}$ \\
\hline $\begin{array}{l}\text { Diabetisch } \\
\text { ohne Insulin }\end{array}$ & 0 & $\begin{array}{l}+0.96 \\
\pm 0.58\end{array}$ & $\begin{array}{l}+1.61 \\
\pm 0.97\end{array}$ & $\begin{array}{r}+2.53 \\
+1.20\end{array}$ & $\begin{array}{l}+3.47 \\
\pm 1.32\end{array}$ & $\begin{array}{l}+4.06 \\
\pm 1.48\end{array}$ & $\begin{array}{l}+5.07 \\
\pm 1.51\end{array}$ & 5 \\
\hline $\begin{array}{l}\text { Diabetisch } \\
\text { mit Insulin }\end{array}$ & 0 & $\begin{array}{l}+0.99 \\
\pm 0.66\end{array}$ & $\begin{array}{l}+1.65 \\
\pm 0.91\end{array}$ & $\begin{array}{l}+2.31 \\
\pm 1.06\end{array}$ & $\begin{array}{l}+2.42 \\
+1.30\end{array}$ & $\begin{array}{l}+3.50 \\
\pm 1.28\end{array}$ & $\begin{array}{l}+3.97 \\
\pm 1.65\end{array}$ & 5 \\
\hline$p$-Wert & & & & & & & $>0.20$ & \\
\hline$\underline{\mathrm{Pi}}$ & 0 & 30 & 60 & 90 & 120 & 150 & 180 & $n$ \\
\hline $\begin{array}{l}\text { Diabetisch } \\
\text { ohne Insulin }\end{array}$ & 0 & $\begin{array}{l}+0.30 \\
\pm 0.05\end{array}$ & $\begin{array}{l}+0.62 \\
\pm 0.10\end{array}$ & - & $\begin{array}{l}+0.80 \\
\pm 0.22\end{array}$ & - & $\begin{array}{l}+1.18 \\
\pm 0.28\end{array}$ & 5 \\
\hline $\begin{array}{l}\text { Diabetisch } \\
\text { mit Insulin }\end{array}$ & 0 & $\begin{array}{l}+0.20 \\
\pm 0.10\end{array}$ & $\begin{array}{l}+0.50 \\
\pm 0.03\end{array}$ & - & $\begin{array}{l}+0.77 \\
\pm 0.10\end{array}$ & - & $\begin{array}{l}+0.94 \\
\pm 0.37\end{array}$ & 6 \\
\hline$p-W e r t$ & & & & & & & $>0.20$ & \\
\hline Kalium & 0 & 30 & 60 & 90 & 120 & 150 & 180 & $\mathrm{n}$ \\
\hline $\begin{array}{l}\text { Diabetisch } \\
\text { ohne Insulin }\end{array}$ & 0 & $\begin{array}{l}+0.52 \\
\pm 0.25\end{array}$ & $\begin{array}{r}+0.90 \\
\pm 0.35\end{array}$ & $\begin{array}{r}+2.24 \\
\pm 0.81\end{array}$ & $\begin{array}{l}+2.90 \\
\pm 0.65\end{array}$ & $\begin{array}{l}+3.31 \\
\pm 0.77\end{array}$ & $\begin{array}{r}+3.60 \\
+0.80\end{array}$ & 5 \\
\hline $\begin{array}{l}\text { Diabetisch } \\
\text { mit Insulin }\end{array}$ & 0 & $\begin{array}{l}+0.46 \\
\pm 0.22\end{array}$ & $\begin{array}{l}+1.03 \\
\pm 0.47\end{array}$ & $\begin{array}{l}+1.70 \\
\pm 0.52\end{array}$ & $\begin{array}{l}+2.04 \\
\pm 0.52\end{array}$ & $\begin{array}{l}+3.04 \\
\pm 0.65\end{array}$ & $\begin{array}{l}+3.10 \\
\pm 0.72\end{array}$ & 6 \\
\hline
\end{tabular}

$p$-Wert

$>0.10$

infusion nicht beeinflußt (s. Tab. 14 u. 15). Das gleiche gilt für die Veränderungen des $L / P-Q$ (s. Tab. 16).

Der Galleflu $\beta$ ist unter Insulin nicht wesentlich verändert (s. Tab. 17).

\section{Diskussion}

Die vorliegenden Untersuchungen lassen 2 sichere direkte Insulineffekte auf die Leber erkennen:

1. Die Nettoglucoseaufnahme normaler Lebern wird gesteigert.

2. Die Nettoabgabe von $\alpha$-Aminosäuren nimmt ab oder es setzt sogar eine Nettoaufnahme von $\alpha$-Aminosäuren ein. Dieser Befund ließ sich an Lebern von normalen und von diabetischen Ratten erheben.

Eine Steigerung der Nettoglucoseaufnahme durch isolierte perfundierte Lebern nach Insulingabe in vitro ist auch von anderen Autoren (an Rattenlebern von HaFt und Miluer [6], sowie von Mortimore [15], an Kaninchenlebern von Huston et al. [8]) festgestellt worden. Diese Befunde entsprechen den von MADIson et al. $[10,11,12,13]$ an Hunden mit porto-cavalem Shunt erhobenen Befunden. Ob die Veränderung der Nettoglucosebilanz Folge einer reduzierten Abgabe neugebildeter Glucose oder einer gesteigerten Glucoseaufnahme ist, läßt sich aus Bilanzuntersuchungen alleine nicht schließen. Es spricht jedoch einiges dafür, daß - zumindest unter unseren experimentellen Bedingungen - eine gesteigerte Utilisation von Glucose durch die Leber für die Anderung der Nettoglucosebilanz verantwortlich zu machen ist: Der Anstieg der Konzentrationen von Lactat und Pyruvat im Medium nimmt unter Insulin zu, was in erster Linie Folge eines gesteigerten Glucoseabbaus sein dürfte.
Die Steigerung der Glucoseaufnahme geht in unseren Experimenten ohne signifikante Verminderung der Harnstoffbildung einher. Die gleiche Konstellation ist auch von HAFT (persönliche Mitteilung) gefunden worden. Lediglich in den Experimenten von MorTIMoRE [15]] ist die Änderung der Glucosebilanz von einer Verminderung der Harnstoffabgabe begleitet.

Man hat versucht, die Größe der Abgabe neugebildeter Glucose in vivo durch verschiedene, Isotopenverdünnungstechniken" zu erfassen. Diese Untersuchungen haben bezüglich des Insulineffektes auf die Glucoseabgabe zu widersprüchlichen Frgebnissen geführt $[2,3,4,5,9,17,18,25,26,28,29]$. Dies beruhte u.a. darauf, daß die Effekte der aus der Insulinhypoglykämie resultierenden Gegenregulationen von den eigentlichen hepatischen. Insulineffekten nicht zu trennen waren. Neuere Untersuchungen, bei denen die Hypoglykämie durch Dauerinfusion von Glucose vermieden wurde, sprechen nach Ansicht der Autoren für eine kurzfristige Drosselung der Glucoseabgabe aus der Leber durch Insulin unter in vivo-Bedingungen (STEELE et al. 1965 [26]). In den gleichen Versuchen wird aber nicht nur die Abgabe neugebildeter Glucose aus der Leber vermindert, sondern auch der Einbau aus dem Plasma stammender ${ }^{14} \mathrm{C}$-markierter Glucose in das Leberglykogen verstärkt (BISHor et al. [1]). Madisox [10] konnte durch gleichzeitige Bestimmung der Nettoglucosebilanz und der Änderungen der spezifischen Glucoseaktivität während der Leberpassage an Hunden mit porto-cavalen Anastomosen zeigen, daß bei geeigneter Dosierung ron Insulin die resultierende Nettoaufnahme von Glucose die Höhe der zuvor mit der Isotopenmethode bestimmten $\mathrm{Ab}$ gabe neugebildeter Glucose weit übersteigen kann. 
Unter Insulin kommt es also in jedem Falle zu einer gesteigerten Aufnahme von Glucose. Es erscheint uns nicht ausreichend bewiesen, ob sich unter diesen Bedingungen überhaupt noch eine Abnahme der endogenen Glucoseneubildung bzw. eine Hemmung der Abgabe neugebildeter Glucose mit der Isotopenmethode alleine nachweisen läßt: Eine Vergrößerung der Glucoseaufnahme führt zu einer Vergrößerung des Glucose-6-Phosphat-Pools in der Leber, kenntlich am Anstieg der spezifischen ${ }^{14} \mathrm{C}$-Aktivität im Leberglykogen (BIsHor et al. [1]). Die spezifische Aktivität der in diesem Pool befindlichen Glucose steigt unter diesen Bedingungen an, auch wenn die endogene Glucoseneubildung nicht herabgesetzt wird. Da die von der Leber abgegebene Glucose vorher den Glucose-6Phosphat-Pool durchlaufen muß, ist auch die spezifische Aktivität der abgegebenen Glucose höher als vorher. Hierdurch kann eine vorübergehende Einschränkung der hepatischen Glucoseabgabe vorgetäuscht werden. Unter Berücksichtigung aller Befunde läßt sich also feststellen, daß Insulin mit Sicherheit die Glucoseaufnahme der normalen Leber direkt und kurzfristig steigert. $\mathrm{Ob}$ auch die Glucoseneubildung in der Leber direkt und kurzfristig durch Insulin vermindert wird, ist noch zweifelhaft. (Dieses Problem wird an anderer Stelle ausführlich diskutiert, s. bei [20].) Die fehlende Wirkung von Insulin auf die Nettoglucosebilanz von diabetischen Lebern steht in Einklang mit der Vorstellung, daß der gestörten Glucoseaufnahme eine herabgesetzte Aktivität der Glucokinase zugrunde liegt (Sols [24]; VIÑ̃ena et al. [27]). Demgegenüber beobachtete MADISON [13] auch bei diabetischen Hunden, die zuvor selbst bei Glucosespiegeln über $33 \mathrm{mMol} / \mathrm{l}$ keine Glucoseaufnahme durch die Leber gezeigt hatten, innerhalb einer Stunde nach Insulingabe eine hepatische Nettoglucoseaufnahme.

Die Ursache der Diskrepanz zu unseren Beobachtungen an isoliert perfundierten Lebern von diabetischen Ratten bleibt unklar. Im übrigen konnte auch WIELAND [30] an der isolierten perfundierten diabetischen Rattenleber keinen Insulineffekt auf die Nettoglucosebilanz beobachten. Auffällig ist, daß unter Insulin sowohl in den Versuchen mit NEFA-reichem als auch mit NEFA-armem Medium die in Kontrollexperimenten mit diabetischen Lebern nach 3 Stunden zu beobachtende Zunahme des Leberglykogengehaltes ausbleibt, obwohl der Ausgangsglykogengehalt bei beiden Gruppen sehr unterschiedlich war. In den Versuchen mit NEFA-reichem Medium stieg der Leberglykogengehalt im Mittel zunächst an, um jedoch in der 3. Stunde stark abzufallen. Dieser Abfall war jedoch nicht von einer verstärkten Nettoglucoseabgabe der Leber begleitet. $\mathrm{Ob}$ es unter der Insulinwirkung im Verlaufe des Versuches zu einer Hemmung der Glucoseneubildung gekommen ist, läßt sich aus unseren Versuchen nicht entnehmen. Die Harnstoff bildung isolierter diabetischer Lebern war zwar unter Insulin geringer, der Unterschied jedoch nicht signifikant.

Die Nettoabgabe von anorganischem Phosphat bleibt in den Versuchen mit Lebern normaler Ratten unter Insulin unverändert, obwohl die Glucoseaufnahme unter diesen Bedingungen signifikant zunirnmt. Eine Erklärung für diesen Befund läßt sich aus den vorliegenden Daten alleine nicht ableiten. Der Befund stimmt aber damit überein, daß isolierte Lebern diabetischer Ratten keine vermehrte Nettoabgabe von anorganischem Phosphat im Vergleich zu Lebern normaler Tiere aufweisen [23].

Auffällig ist, daß der Effekt von Insulin auf die Netto-Aminosäurebilanz keinen Unterschied zwischen Lebern von normalen und diabetischen Ratten ergab. Dies steht im Gegensatz zu älteren Befunden von Pexhos und Kranu [16], die nach in vitro-Insulingabe eine signifikante Zunahme des ${ }^{14} \mathrm{C}$-Leucineinbaus in Leberproteine von isolierten perfundierten Lebern leicht diabetischer, nicht dagegen schwer diabetischer Ratten sahen. Auch MrLLER [14] vertrat die Ansicht, daß nur bei Perfusion von Lebern leicht diabetischer Tiere ein in vitro-Effekt von Insulin auf die Aminosäurebilanz nachweisbar sei. Die Steigerung der Aminosäureaufnahme durch Insulin ohne gleichzeitige Steigerung der Harnstoffbildung weist darauf hin, daß der Effekt in erster Linie durch eine Steigerung des Aminosäureeinbaus in Proteine zustande kommt. Die möglichen Ursachen des gesteigerten Aminosäureeinbaus werden an anderer Stelle ausführlich diskutiert [20]. Frwähnenswert ist jedoch, daß HAFT und Mrluer [7] eine Besserung der Nettoaminosäurebilanz isolierter perfundierter normaler Rattenlebern auch durch starke Erhöhung des Glucoseangebotes erzielen konnten. Dem dürfte entsprechen, daß wir bei der Verwendung von Fructose $(11,1 \mathrm{mMol} / \mathrm{l})$ anstelle von Glucose im Perfusionsmedium ebenfalls eine deutliche Besserung der Nettoaminosäurebilanz beobachten konnten (s. Abb. 6). Es spricht vieles dafuir, daß die

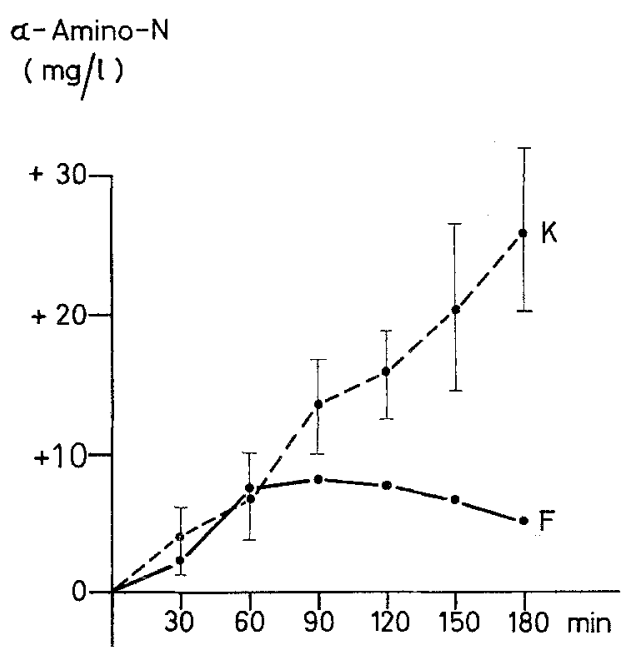

Abb. 6. Änderungen der a-Amino-N-Konzextration im Medium wăhrend der Perfusion isolierter Lebern yon normalen Ratten. $\mathrm{K}=$ Kontrollexperimente mit $11.1 \mathrm{mMol} / 1$ Glucose im Medium (Mittelwertskurve mit Standardabweichungen), $\mathbf{F}=$ Mittelwertskurve aus 2 Experimenten mit $11.1 \mathrm{mMol} / \mathrm{l}$ Fructose im Medium. Die Konzentrationsänderungen wurden auf $10 \mathrm{~g}$ Leber sowie die $=0$ gesetzten Ausgangskonzentrationen bezogen 
insulin-bedingte Steigerung der Proteinsynthese Folge einer verbesserten Bereitstellung energiereicher Phosphate in den für die Proteinsynthese entscheidenden intracellulären Funktionsräumen (Nucleinsäuresynthese, Aminosäureaktivierung, AminosäuretransferMechanismus) sein könnte.

Die Kinetik der Aufnahme freier Fettsäuren durch die Leber wurde durch Insulin nicht signifikant beeinflußt (s. Abb. 3 u. 5). Auch die Nettoketonkörperabgabe normaler Lebern weist unter Insulin keine signifikante Veränderung auf. Die Ketonkörperabgabe diabetischer Lebern ist zwar in den Versuchen mit Insulin etwas geringer, jedoch sind nur die nach 150 Minuten gemessenen Mittelwerte signifikant unterschieden. Diese Differenzen sind u.E. weniger dem Einfluß des Insulins als Unterschieden im Grad der diabetisch bedingten Leberverfettung zuzuschreiben. Man muß jedoch diskutieren, ob nicht Insulin durch Steigerung der im Diabetes eingeschränkten Fettsäuresynthese zu einer Verminderung der Ketonkörperbildung führt. Von HAFT und MrLLER [6] ist nämlich eine Beschleunigung des Einbaus. von C14-Acetat in langkettige Fettsäuren durch isolierte perfundierte Lebern von - allerdings nur leicht - diabetischen Ratten nach Insulingabe in vitro beschrieben worden. Nach unseren eigenen Befunden scheint der Einschränkung der Fettsäuresynthese aber nur eine untergeordnete Rolle bei der diabetischen Ketose zuzukommen: Nach intraportaler Infusion von $\mathrm{Na-Capronat} \mathrm{nahm} \mathrm{die}$ Ketonkörperbildung durch Lebern schwer diabetischer ketotischer Ratten nicht stärker zu als durch Lebern normaler Tiere [21, 22], obwohl die Fettsäuresynthese unter diesen Bedingungen sicher maximal eingeschränkt war. Auch die übrigen Parameter lassen im einzelnen keine signifikanten Insulineffekte erkennen. Im ganzen deuten jedoch die kleinen, unter Insulin feststellbaren Veränderungen auf eine allgemeine Verbesserung der Stoffwechsellage unter Insulin hin: Die Mediumkonzentrationen ron Lactat und Pyruvat steigen stärker an, die Konzentrationsanstiege von Harnstoff, anorganischem Phosphat und Kalium erfolgen in Experimenten mit diabetischen Lebern unter Insulin langsamer, die Galleproduktion normaler und diabetischer Lebern ist im Mittel unter Insulin verstärkt. Es liegt nahe, dies als Folge eines einzigen hepatischen Insulineffektes anzusehen, über dessen Natur bisher aber keine klaren Kenntnisse vorliegen.

\section{Literatur}

[1] Bishop, J.S., R. Stefele, N. Altszuler, A. Dunn, C.B. JERKNES and R.C. DE Bodo: Effects of insulin on liver glycogen synthesis and breakdown in the dog. Amer. J. Physiol. 208, 307 (1965).

[2] Bodo, R. C. de. R. Steele, N. Altszuler, A. Dunn, D.T. Armstrong and J.S. BIshop: Further studies on the mechanism of action of insulin. Metabolism $\mathbf{8}$, $520(1959)$.

[3] - - - and J.S. Bishor: Effects of insulin on hepatic glucose metabolism and glucose utilization by tissues. Diabetes 12, 16 (1963).
[4] Dunn, D.F., B. Friedmann, A.R. MaAss, G.A. ReICHaRd and $\mathrm{S}$. WeINHOUSE: Effect of insulin on blood glucose entry and removal rates in normal dogs. J. biol. Chem. 225, 225 (1957).

[5] Franckson, J.R.M., Y. Arnould, W. Malaisse and V. ConaRD: Glucose metabolism in the normal anesthetized dog injected successively with antiinsulin serum and insulin. Diabetes 13, 532 (1964).

[6] HAFT, D.E., and L.L. MiLLER: Alloxan diabetes and demonstrated direct action of insulin on metabolism of isolated perfused rat liver. Amer. J. Physiol. 192, 33 (1958).

[7] - Enhanced sugar uptake fails to stimulate the insulin effect on lipogenesis in the isolated perfused rat liver. Amer. J. Physiol. 193, 469 (1958).

[8] Hustow, C.J.W., L.C. Adays, R.A. Field and W.V. McDermote jx.: Effect of insulin on glucose uptake by the isolated perfused canine liver. Lancet 1962 I, 357.

[9] Katant, N., Th.R. Csorba and N. Heller: Effect of insulin on glucose production and utilization in diabetes. Metabolism 12, 1100 (1963).

[10] Madison, L.L.: The role of insulin in controlling carbohydrate metabolism in the liver. Vortrag auf dem 5. Kongreß der International Diabetes Federation, Toronto 1964 .

[11] - R.H. UNaer and K. Rencz: The physiological significance of secretion of insulin into portal circulation: II. Effect of rate of administration of glucagon-free insulin on magnitude of peripheral and hepatic actions. Metabolism 9, 97 (1960).

[12] B. Combes, R. Adams and W. Strickland: The physiological significance of the secretion of endogenous insulin into the portal circulation. III. Evidence for a direct immediate effect of insulin on the balance of glucose across the liver. J. clin. Invest. 39, $507(1960)$.

[13] - D. Mrbane, F. Lmcoce and B. Combes: Physiological significance of the secretion of endogenous insulin in to the portal circulation. $V$. The quantitative importance of the liver in the disposition of glucose loads. Diabetes 12, 8 (1963).

[14] Mrrler, L.L., W.T. Burke and D.E. HafT: in "Some aspects of amino acid supplementation", S. 44, Rutgers Univ. Press, Rallway, New Jersey 1956.

[15] Montmone, G. E.: Effect of insulin on release of glucose and urea by isolated perfused rat liver. Amer. J. Physiol. 204, 699 (1963).

[16] Pentros, J.C., and M.E. Krafu: Stimulus of leucine incorporation into perfused liver protein by insulin. Amer. J. Physiol. 204, 140 (1963).

[17] Reichard, G.A. jr., A.G. JACobs, P. Kimbed, N.J. Hochella and S. Wernhouse: Blood glucose replacement rates in normal and diabetic humans. J. appl. Physiol. 16, 789 (1961).

[18] Shommaker, W.C., R. Mahter and J. Ashmore: The effect of insulin on hepatic glucose metabolism in the unesthetized dog. Metabolism 8, 494 (1959).

[19] Söltrg, H.D.: Der Stoffwechsel der alloxandiabetischen Rattenleber und seine Beeinflussung durch Insulin und orale Antidiabetica; gleichzeitig ein Beitrag zum Problem der Entstehung der diabetischen Ketose. Habilitationssehrift, Univ. Göttingen 1965.

[20] - Wirkungsmechanismus des Insulins: Die Insulinwirkung auf das Lebergewebe, in ,Diabetes mellitus, Pathophysiologie und Klinik" (im Druck).

[21] - R. KATTERMANN and H. Schmot: The relationship between the eytoplasmatic redoxstate and ketogenesis in the liver cell, and the problem of triosephosphate block in diabetes mellitus. Vortrag auf dem 5. Kongreß der International Diabetes Federation, Toronto 1964.

[22] - - - and P. KNEER: The redoxstate of $\mathrm{NAD}^{+} /$$\mathrm{NADH}$-systems in rat liver during ketosis, and the 
so called "triosephosphate block". Biochim, biophys. Acta 115, 1 (1966).

[23] - R. Koschel, W. Drägert, P. Kneer und W. CreutzFeld : Die Wirkung von Insulin auf den Stoffwechsel der isolierten perfundierten Leber normaler und alloxandiabetischer Ratten. I. Der Stoffwechsel isolierter perfundierter Lebern von normalen und alloxandiabetischen Ratten unter verschiedenen experimentellen Bedingungen. Diabetologia 2, 20 (1966).

[24] Sols, A.: Glucokinase, Hexokinase, and the regulation of glucose phosphorylation. Vortrag auf dem 6. Internat. Kongreß für Biochemie, New York 1964.

[25] STEELE, R.: Influences of glucose loading and of injected insulin on hepatic glucose output. N.Y. Acad. Sci. 82, 420 (1959).

[26] - J.S. Bishop, A. DunN, N. Attszuler, I. Rathgeb and R.C. DE BODo: Inhibition by insulin of hepatic glucose production in the normal dog. Amer. J. Physiol. 208, 301 (1965).

[27] VIÑUela, E., M. Salas and A. Sols: Glucokinase and hexokinase in livers in relation to glycogen synthesis. J. biol. Chem. 238, PC 1175 (1963).

[28] Wall, J.S., R. Steele, R.C. DE Bodo and N. ALTSZULER: Effect of insulin on utilization and production of circulating glucose. Amer. J. Physiol. 189, 43 (1957).

[29] Weinhouse, S., B. Friedmann and G. Reichard: Effects of insulin on hepatic glucose production and utilization. Diabetes 12, 1 (1963).

[30] Wifland, O.: Diskussionsbemerkung auf dem 1. Kongreß der Europ. Gesellschaft Diabetol., Montecatini Therme 1965 .

Priv.-Doz. Dr. Hans-Dieter Sölrng Medizinische Universitätsklinik 34 Göttingen 